IZA DP No. 8865

Estimating the Size of External Effects of Energy Subsidies

Simon Commander

Zlatko Nikoloski

Maria Vagliasindi

February 2015 


\title{
Estimating the Size of External Effects of Energy Subsidies
}

\author{
Simon Commander \\ Altura Partners, \\ IE Business School and IZA

\section{Zlatko Nikoloski} \\ London School of Economics
}

$\underset{\text { World Bank }}{\text { Maria Vagliasindi }}$

\section{Discussion Paper No. 8865 \\ February 2015}

\author{
IZA \\ P.O. Box 7240 \\ 53072 Bonn \\ Germany \\ Phone: +49-228-3894-0 \\ Fax: +49-228-3894-180 \\ E-mail: iza@iza.org
}

\begin{abstract}
Any opinions expressed here are those of the author(s) and not those of IZA. Research published in this series may include views on policy, but the institute itself takes no institutional policy positions. The IZA research network is committed to the IZA Guiding Principles of Research Integrity.

The Institute for the Study of Labor (IZA) in Bonn is a local and virtual international research center and a place of communication between science, politics and business. IZA is an independent nonprofit organization supported by Deutsche Post Foundation. The center is associated with the University of Bonn and offers a stimulating research environment through its international network, workshops and conferences, data service, project support, research visits and doctoral program. IZA engages in (i) original and internationally competitive research in all fields of labor economics, (ii) development of policy concepts, and (iii) dissemination of research results and concepts to the interested public.
\end{abstract}

IZA Discussion Papers often represent preliminary work and are circulated to encourage discussion. Citation of such a paper should account for its provisional character. A revised version may be available directly from the author. 
IZA Discussion Paper No. 8865

February 2015

\section{ABSTRACT}

\section{Estimating the Size of External Effects of Energy Subsidies ${ }^{1}$}

It is widely accepted that the costs of under-pricing energy are large, whether in advanced or developing countries. This paper explores how large these costs can be by focussing on the size of the external effects that energy subsidies in particular generate in two important sectors - transport and agriculture - in two MENA countries, Egypt (transport) and Yemen (agriculture). Our focus is mainly on the costs associated with congestion and pollution as well the impact of under-priced energy for depletion of scarce water resources including through crop selection. Quantifying the size of external effects in developing countries has received relatively little analytical attention, although there is a significant body of literature for the advanced world. By building on earlier research, as well as employing the UN ForFITS model we are able to provide indicative estimates of the external costs of energy subsidies, as manifested in congestion and pollution. Our estimates using simulations indicate that these costs could be materially reduced by elimination or reduction of energy subsidies. We are also able to describe the impact of energy subsidies on water consumption in a region where water resources are particularly limited. As such, our findings provide further evidence of the adverse and significant consequences of subsidising energy.

JEL Classification: O13, R41, Q41, Q53, I15

Keywords: energy subsidies, pollution, congestion, health effects of energy subsidies

Corresponding author:

Simon Commander

Altura Partners

E-mail: scommander@alturapartners.org

\footnotetext{
${ }^{1}$ Our special thanks go to Shanta Devarajan and Junaid Ahmad for their excellent advice and support throughout the preparation of this paper and to Hanane Ahmed, Pierpaolo Cazzola, Ziad Nakat, Maurice Saade, Andreas Schliessler, Steven Schonberger, Caroline van den Berg, and Patricia Veevers-Carter for their helpful suggestions.
} 


\section{Introduction}

The under-pricing of energy - notably fuel products - has a predictable, and sometimes significant, impact on demand. Energy subsidies - if persistent - can also affect the dynamic factor mix, creating a bias for energy intensive production and usage. Indeed, existing evidence from MENA indicates that pervasive energy subsidies have created large distortions in markets and investment choices.

One consequence of the under-pricing of energy that is relatively under-studied and quantified concerns the external costs that arise through the pollution and congestion that result from excess use of fossil-fuel-powered vehicles, as well as the associated transport modal choices. For example, evidence from Egypt, notably Cairo, indicates massive - and growing - congestion with high levels of associated pollution, part of which can be attributed to the excess demand for private vehicles and fuel consumption that results from the large subsidies that fuels attract. While transport - particularly road transport - may offer a particularly stark illustration of the external costs, significant costs may also arise in other sectors. In agriculture, fuel subsidies depending on the institutional and pricing arrangements for water supply - can lead to overrapid depletion of water reserves and to crop selection that may principally reflect the underpricing of water rather than the comparative advantage of the country or region. Similarly in manufacturing, the sectoral mix of output and employment may be directly affected by the price of energy that may also influence the choice of technology. When energy prices are low, production will tend to be energy intensive and wasteful and this is often associated with relatively high rates of pollution and other external effects.

The magnitude of external effects associated with the under-pricing of energy has not been consistently measured. However, the IMF (2013) has attempted to estimate the difference between pre- and post-tax subsidies where the latter include a tax aimed at charging for external effects linked to pollution, $\mathrm{Co} 2$ emissions, congestion and so on, as well as an additional tax on energy consistent with the standard indirect tax rates applying in the country. Although their calculation is clearly very approximate, it provides an initial reference point. For Egypt the gap between pre-and post-tax subsidies expressed as a share of government revenues was over 8 percentage points (30.6 versus 39.1) in 2011. This discrepancy is far from trivial and for reasons that will become clear later, is likely to be an under-estimate.

This paper is exploratory - not least because of serious data limitations - and as a consequence we restrict our attention to understanding the size of external effects of energy subsidies in two sectors - transport and agriculture - focussing, in the first instance, on the congestion and pollution costs and, in the second instance, focussing on resource (water) depletion and crop selection. At this point, two locations are selected - Cairo in Egypt for the transport dimension and Yemen for the agriculture dimension.

The paper is organised as follows. Section 2 identifies the external effects that we are interested in and the main channels or processes through which energy pricing affects the main variables of interest. It then outlines how they affect the performance of economic actors and the economy as a whole. In discussing the main methodological and empirical issues it also reviews the results of earlier, relevant studies. Section 3 then provides evidence for transport from the MENA 
region concerning both context and selected outcomes. Section 4 then looks in more detail at Egypt starting with an overview of fuel pricing before turning to estimates of the costs of congestion and pollution. Section 5 is concerned with the water-energy nexus and the ways in which mispricing of energy affects water use and depletion with a specific emphasis on Yemen. Section 6 provides a first, tentative estimate of the costs of pollution and congestion drawing on data contained in a recent World Bank study of Cairo. These measures are linked to a wider health/productivity indicator initially assembled by the World Health Organisation, termed DALY. We provide a simple simulation of the impact of energy price increases (viz., reduction in subsidy) on these variables. Section 7 lays out a more extended modelling framework (relying on the UN ForFITS model) that we apply to measure the impact of energy pricing on pollution, congestion and $\mathrm{Co} 2$ emissions, as well as capturing the interactive effects relating to modes of transport and substitutions across modes. More specifically, this section represents a simulation exercise that links various scenarios (changes in international oil prices and reduction in domestic subsidies, both in medium and short term) to the overall CO2 emissions. The results from this exercise are then used to quantify the cumulative health effect of energy subsidies reduction.

\section{Transport: external effects and the main channels}

Vehicular transport reliant on fossil fuels generates a range of effects that have economic costs. These can be grouped under a number of rubrics. The first relates to the direct effect of emissions. There is a substantial body of evidence that vehicle emissions can affect not only individuals' health but also have a wider effect on climate change variables, the consequences of which may be both local and global, although these may not be easily quantifiable. Regarding the first channel, the usual way of thinking about this is to try and estimate what the emissions associated with vehicle usage do to a set of health indicators and, by implication, to productivity. A negative shock to health - whether through a fall in life expectancy or an increase in morbidity - will have a direct impact on productivity and potentially on growth. For simplicity, this can be termed the productivity channel where the link is from use of a particular set of transport technologies to emissions to health outcomes. In these instances, there may be a complex lag structure and some important non-linearities. For example, emissions may reach certain thresholds beyond which health outcomes deteriorate at an accelerated pace. But fossil-fuel transport use will also tend to affect productivity through further related channels. Notably, congestion - resulting from an excess of vehicles for a given stock of transport infrastructure will affect the amount of time that people require for, inter alia, getting to and from work and hence act as an effective subtraction from working time. There may in addition be a host of other more intangible effects of a psychological nature that can have an impact on individuals' behaviour and productivity. Anecdotal data from a wide range of locations - not just in MENA - suggests that these effects can be large and highly deleterious.

To this point, the broad problem has been framed in terms of an impact of a broad technology on outcomes at the level of individuals with that impact then aggregating to impose some economy-wide impact. However, our problem in this paper is narrower. Specifically, we are interested in the marginal impact of an energy price subsidy - defined as the deviation from a market price - on demand and ultimately through consumption on the external indicators, 
congestion and pollution in the case of transport, and through these the wider economic and social costs that are imposed. As such, we are interested in measuring the incremental impact on pollution and congestion that result from the under-pricing of energy.

Our aim at this stage is to arrive at some initial benchmark estimates of the scale of these costs using a variety of measures. An important caveat is in order at this point. Such calculations tend to require highly disaggregated information, whether on types of vehicle use and occupancy, as well as on outcome variables, whether it be congestion and/or pollution themselves or associated indicators, such as accidents. There is also the link to be made between the variables of interest - congestion and pollution - and individuals' productivity. Each of these steps is relatively data-intensive. Yet, the reality is that for most developing countries, including in MENA, such data are not available or are limited in coverage and quality. This necessarily makes precision in calculation difficult, if not impossible. To surmount these major limitations, we have, in the initial part of the paper, recourse to values or parameter estimates that may be drawn from more data-rich contexts, either from advanced economies or other MENA countries.

\subsection{Agriculture}

Our main focus in this paper is on how energy subsidies might have an impact upon: (i) water usage (primarily through affecting the cost of pumping) and, (ii) crop selection. Much of the available literature has focussed on India where two main channels though which energy subsidies impact upon the economy have been identified. First, they have encouraged farmers to withdraw groundwater at high, probably unsustainable, rates. The rapid rates of groundwater extraction lowers groundwater tables, which in turn requires more energy to pump water to the surface: this process creates a trap in which eliminating or lowering the subsidy leads to groundwater extraction costs that would make agricultural production unprofitable for many farmers. Second, the excessive use of electricity in water extraction makes electricity more expensive for the non-farm economy, inhibiting thus the non-farm economy's ability to absorb labour from the farm economy, and hence, serves as a drag on the county's economic growth potential (IFPRI (2011)).

Based upon this, Nelson et al. (2013) use a computable general equilibrium model to evaluate the economic impact of groundwater depletion on the agricultural and non-agricultural sectors of Punjab and the rest of India. Their findings suggest that eliminating electricity subsidies for irrigation could lead to less groundwater consumption and lower agricultural production levels and agricultural income, while increasing the productivity and income of the non-farm sectors (via decreased energy prices). When cutting the electricity subsidy, the results suggest that farmers could decrease water use by $30 \%$, while minimally hurting agricultural value-added economy (a decrease of approximately 5\% of income in 2007 dollars). Perhaps more surprising, is the finding that this could be associated with a very large increase in manufacturing output.

Additional methodologies for assessing the link between energy and agriculture include inputoutput models. In the Malaysian context, Bekhet (2010) uses an input-output model to estimate the link between three energy sectors and agriculture for the period 1991-2000. The analysis shows that the agriculture sector is heavily based upon inputs from petrol and coal industries, most notably because of subsidized energy products. Given the weak linkages between 
agriculture and electricity and gas sectors, the paper advocates switching to these energy products whenever possible.

Using co-integration analysis, Jha et al. (2012) analyse the relationship between agriculture and energy use. Their conclusion is that agriculture in India has become very energy intensive, thus requiring further technological change involving more energy efficient farm machinery and irrigation systems. However, concentrating solely on technically improving the efficiency of pumps might further aggravate the speed at which water tables are depleted. There is thus a need to first optimise water demand in agriculture through a broader approach to the water-energy nexus. This would include massive state investments to improve surface irrigation, groundwater table management, irrigation technologies, agricultural practices (including organic agriculture and crop diversification) as well as food procurement policies.

The available literature suggests that the problem of water depletion is both technical (for example, imposing metered tariffing for water), and political. IFPRI sums up the policy recommendations for addressing groundwater depletion due to excessive energy use as, (1) options linked to electricity supply: (a) meter use and increase agricultural tariff; (b) restrictions on timing of electricity supply; (c) possible restrictions on choice of crops by withdrawing free electricity or subsidy and (2) options not directly linked to electricity supply, including, (a) increased regulation; (b) community-based groundwater management; (c) state ownership and management of bore wells; (d) promotion of less water intensive crops and cultivation practices and, (e) groundwater-recharge measures (IFPRI (2011)).

\subsection{Measuring productivity-affecting outcomes}

\section{Pollution}

While the measures that are widely used to quantify pollution (either pollution in general or air pollution due to traffic) are largely uncontroversial, what we are primarily interested in is the impact of those pollution outcomes on persons. Here, a widely used measure is the WHO metric of DALY or Disability-Adjusted Life Year. The basic idea is that a combination of increased mortality/morbidity (i.e. increase of deaths and increase of years lived in sub-optimal health) will result from higher levels of emissions, as measured, for example, by particles (PM10, PM2.5, Pb). The calculations are based on epidemiological functions, whose coefficients capture the increased level of mortality and morbidity beyond the particles' threshold point $(20 \mathrm{mg}$ per cubic metre for PM10, $10 \mathrm{mg}$ per cubic metre for PM2.5 etc.). DALYs for a disease or health condition are calculated as the sum of the Years of Life Lost (YLL) due to premature mortality in the population and the Years Lost due to Disability (YLD) for people living with the health condition or its consequences. For our purposes, DALY would be a sum of deaths due to vehicle-specific air pollution (multiplied by the average life expectancy in the city/country) and YLD of the (vehicle specific) air pollution. Calculating YLD is a bit more complex but in essence it is a product of the number of incident cases of disease caused by air pollution (respiratory, cardio-vascular), disability weight and average duration of the case until remission to death. The disability weight (also called the dose function) depicts the relationship between the pollutants (lead $(\mathrm{Pb}), \mathrm{CO}, \mathrm{Co} 2$ and particulates such as PM10, PM2.5) and specific health variables 
(incidence of bronchitis, hospital admissions, emergency room visits etc.)). The specific parameters of the dose function for air pollution have been reasonably well studied (for example, Mayeres et al (1996), WHO (1999), Ostro et al (2004), Pope et al (1995, 2002 and 2009), as well as the EU project ExternE). The final estimate of the social cost of pollution would be a product of the DALY and average GDP per capita (for a given period) ${ }^{2}$.

\section{Congestion}

There is also a large literature on congestion. Recent studies include Roobuste et al (2001), Mizutani et al (2011) with their common focus on estimating the social costs of traffic congestion. Measuring these costs is often done in in three steps. The first is to estimate the daily time lost due to traffic congestion. Time loss is specified as a function of traffic volume and road length and speed. The second is to calculate the annual time loss - or opportunity cost - due to traffic congestion. Finally, the monetary value of traffic congestion is calculated. Time loss caused by congestion relies on a measure of the value of time. For example, detailed studies have calculated the value of time for each vehicle type, as vehicle types serve as proxies for different groups of people and hence different opportunity costs (see INFRAS/IWW 2004). Additional costs of vehicular use can include accidents and noise. Again, for simplicity, studies tend to rely on unit costs for specific modes of transport. In short, measurement of congestion costs boils down to: (a) loss of time and its value; and (b) excess energy use due to recurrent and nonrecurrent delays.

\section{Intermodal choice}

Fuel subsidies can affect not only aggregate demand but can also have implications for the modal mix, often with complex feedbacks. For example, Forkenbrock $(1999,2001)$ has estimated the external costs of intercity truck freight and railway transportation looking at pollution, traffic accidents and noise, as well as climate change ${ }^{3}$. Another recent study done for Barcelona, finds that the external costs of cars and motorcycles are 9 Euro cents per km trip; almost seven times larger than the external costs of public transport, estimated at 1.3 Euro cents per $\mathrm{km}$ trip. Although, that study does not estimate the indirect cost of freight (railway vs. road), the same logic could be applied in calculating those numbers as well (Robuste et al., 2001).

A significant proportion of the literature is devoted to studying the determinants of modal choice (mainly for passenger transport). Among the main factors are socio-demographic commonly measured by age, gender, occupation, education, income, household composition and car availability (De Witt et al., 2013). The most robust relationship is between income and car ownership. More rudimentary models only consider income as the only determinant of car ownership (Schaefer, 2000, for instance etc.). Similarly, a paper on Jordan (Al-Ghandor et al., 2013) using historical data and multinomial regression analysis finds that an increase in income

\footnotetext{
2 This seems to be the dominant method. See, for instance, Doumani (2011) in the case of Cairo, Mizutani et al. (2011) in the case of Japan. Monzon and Guerrero (2004) for the case of Madrid use a simpler method of valuing the cost of pollution as the sum of deaths due to pollution (times GDP per capita) and total excess hospital costs due to increased hospital admissions as a result of increased pollution. ${ }^{3}$ The unit costs for air pollution, climate change and noise are all taken from INFRAS/IWW study (1994) and its
subsequent updates.
} 
leads to increased vehicle ownership, which, in turn, increases gasoline consumption. The literature also looks at spatial indicators, such as density, diversity, proximity to infrastructure and services, frequency of public transport and parking. Most of the literature here focuses on the urbanization/public transport nexus and finds a positive link between urbanization and reliance on public transport (Camagni et al., 2002; Limtanakool et al., 2006), although with the caveat that this research is based on findings from advanced economies. A further strand concentrates on journey characteristics including travel motives, distance and time, travel costs and so on. A paper on Spain (Rojo et al., 2012) focusing on inter-city travel, uses discrete choice analysis to suggest that passengers tend to value time the most. Travel cost is also well documented as an important determinant of modal choice (De Witt et al., 2013), with consumers being sensitive to price changes, but the extent to which depending on several factors, including the purpose of the trip etc., (Annema, 2002; Litman, 2004). In addition, socio-psychological factors have also been considered. Some of these (attitudes, lifestyle, experience) are largely a function of income, so the literature suggest a somewhat similar relationship between them and decisions on a modal choice (De Witt et al., 2013). Needless to say, most of this research has been conducted in advanced economies.

A separate strand of the literature has focused on simulating/studying the impact of various policy actions on the modal choice (and in addition on car ownership/gasoline consumption and CO2 emissions). For Jordan, Al-Ghandor et al., (2013) do some projections of gasoline consumption with the current level of subsidies and with an alternative policy scenario of removing fuel/energy subsidies. The findings suggest that with current pricing policies gasoline consumption is expected to rise by $1.8 \%$ a year (in line with the increase in per capita income/car ownership). Reduction of energy subsidies could reduce the increase of gasoline consumption to $0.5 \%$ a year. A similar study on China (He et al., 2013) also simulates fuel consumption/Co2 emissions in China under various scenarios. A paper on Australia (Stanley et al., 2013) considers various policies that have a direct impact on the modal choice and therefore on greenhouse gas emissions (GHG): (i) reduce urban car kilometres travelled; (ii) increase the share of urban trips performed by walking and cycling; (iii) increase public transport's mode share of urban motorised trips; (iv) increase urban car occupancy rates; (v) reduce forecast fuel use for road freight; (vi) improve vehicle efficiency. Of all of the factors, the paper suggests that increasing fuel efficiency (along with behavioural changes in buying more fuel efficient cars) could significantly reduce (GHG). The paper also suggests comprehensive congestion charging as a possible way forward. Other studies of advanced economies report mixed findings on the likely efficacy of policy. For example, Small (2012) simulates the impact of various energy policies for passenger motor vehicles in the USA. He finds that the impact of various policies suggested/debated would be modest. His conclusion is that higher fuel taxes seem to be the best policy option as their effects set in quickly and are not counteracted by the "rebound effect". Furthermore, a high fuel tax can be combined effectively with a policy mandating new-vehicle fuel efficiency, providing greater effectiveness at a unit cost comparable to that of the fuel tax alone. The paper (even though it does not include any external costs of driving in the model (accidents, congestion etc.) suggests that a fuel tax discourages vehicle travel. A paper by Rentziou et al. (2012) offers similar findings. The wider literature looking at fuel price elasticities unambiguously finds that fuel price increases lead fuel consumption to decline, in the short-term by reducing total vehicle travel and driving speeds, and shifting travel to more fuel-efficient 
vehicles, and in the long-term by increasing vehicle fuel economy and land use accessibility. An overview of recent papers puts these elasticities in the range of -0.1 to -0.25 in the short run and -0.2 to -0.3 in the long run.

\section{Evidence for the transport sector in MENA region}

This section reviews the rather fragmentary evidence from the region on the costs associated with transport.

\subsection{Road accidents}

While deaths from road transport tend to be inversely related to the income level of the country and health losses due to pollution tend to be higher in rich countries or regions, MENA stands out as an exception, ranking high on both accounts.

Motorized road transport imposes a large toll on health in the MENA region, which is only surpassed by South Asia and Sub-Saharan Africa in terms of rates of deaths due to road crashes. Further, the death toll appears to have been growing significantly, amounting to more than 73,500 lives in 2010. The rate of road injury deaths has decreased from 1990 to 2010 by less than 10\% compared with the much more substantial decline - close to $50 \%$ recorded in the European Union and close to 30\% in Europe and Central Asia.

The occupants of vehicles account for the bulk of deaths (>60\%) in the MENA region in 2010. Pedestrians account for more than $20 \%$ of road injury deaths in the MENA region, compared to $40 \%$ in South Asia and Sub Saharan countries.

Figure 1: Road deaths, 1990-2010 and disaggregation of victims (\%)
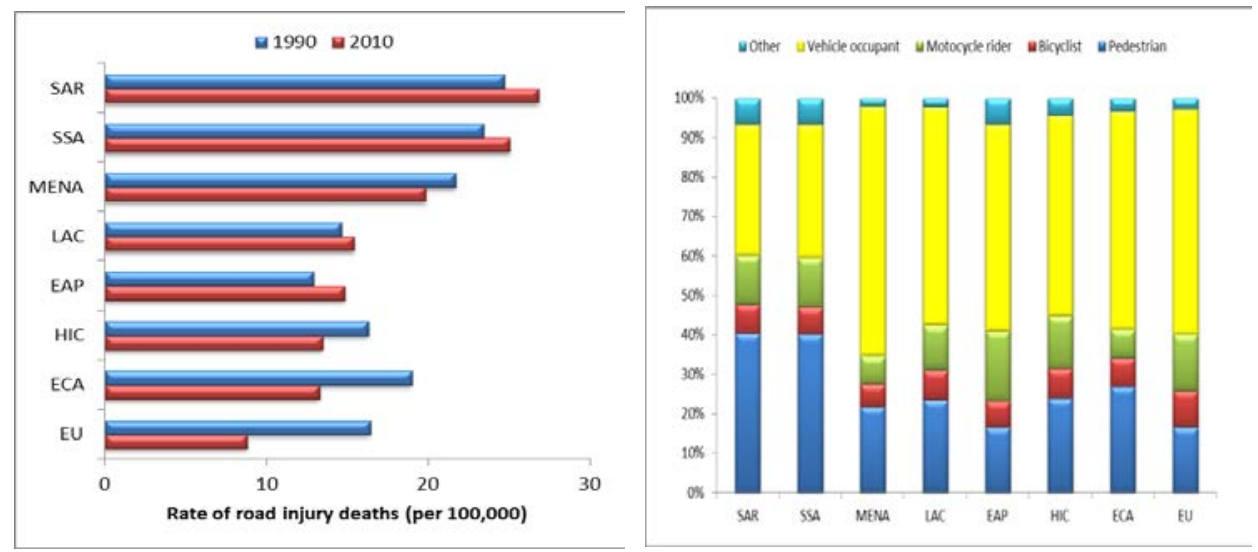

Source: Authors' elaboration based on Institute for Health Metrics and Evaluation's Global Burden of Disease (GBD) dataset

Within the MENA region there is also substantial variation across countries. Egypt is - after Iran

- the country most affected by road injury deaths in absolute terms. Further, both countries have recorded an increase in road injury deaths. 
Figure 2: Road deaths, 1990-2010 (absolute number and per 10,000 people)

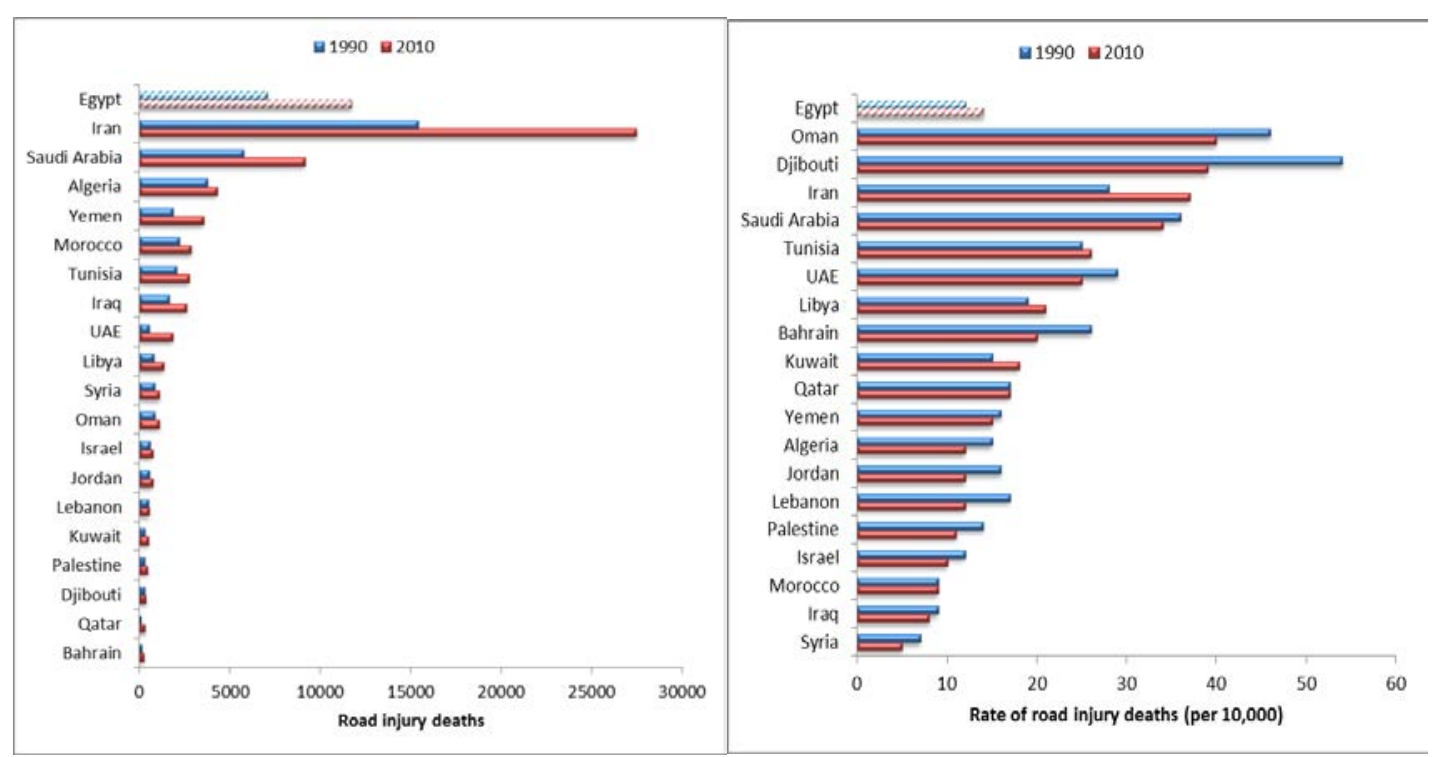

Source: Authors' elaboration based on Institute for Health Metrics and Evaluation's Global Burden of Disease (GBD) dataset

The data also show a significant difference in the rate of road injury deaths between countries with below and above average fuel transport prices (both gasoline and diesel). While this may well be explained by a combination of factors, it is possible that reducing subsidies may contribute to reducing the toll in terms of human lives.

Figure 3: Difference in road deaths for countries with above and below average fuel prices

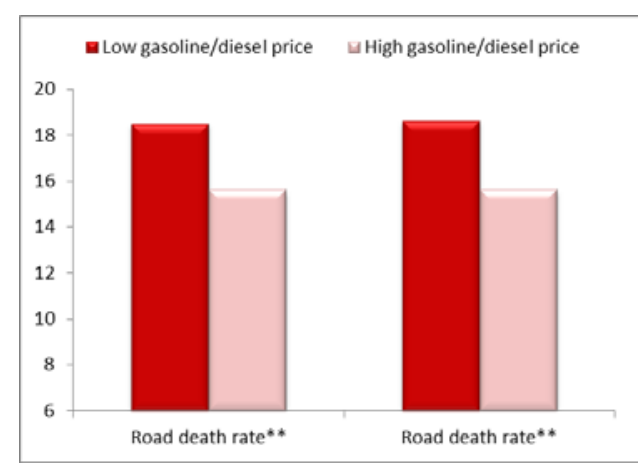

Note: ${ }^{*}$ denote significance of t-test between the average groups at $5 \%$ confidence level

Source: Authors' elaboration based on Institute for Health Metrics and Evaluation's Global Burden of Disease (GBD) dataset

Non-fatal road injuries, including those warranting hospital admission and medical care are also quite high in the MENA region, which is only second to South Asia in terms of rates of nonfatal road injuries. 
Figure 4: Difference in road deaths between countries with above and below average fuel prices

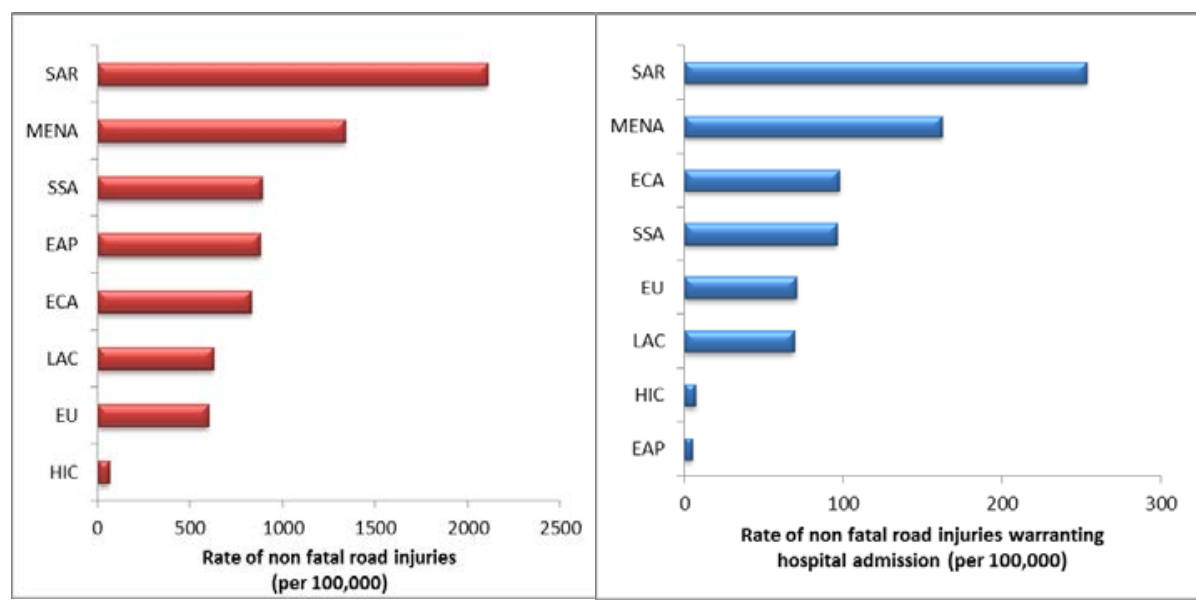

Source: Authors' elaboration based on Institute for Health Metrics and Evaluation's Global Burden of Disease (GBD) dataset

The data also show some difference in the rate of non-fatal road injury deaths between countries with below and above average fuel transport prices (both gasoline and diesel). With similar caveats as above, this might suggest that reducing subsidies - coupled with an effective road safety programme - may contribute to reducing non-fatal injuries due to road accidents.

Figure 5: Difference in average non-fatal injuries rates for countries with above and below average gasoline/diesel prices

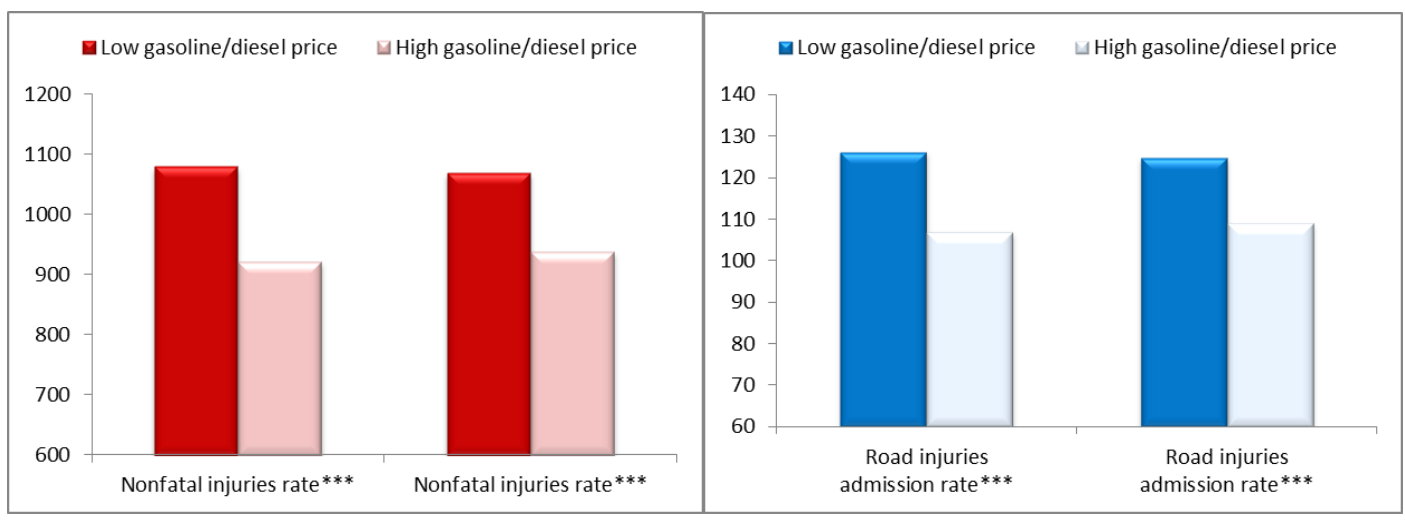

Note: *** denote significance of t-test between the average groups at $1 \%$ confidence level

Source: Authors' elaboration based on Institute for Health Metrics and Evaluation's Global Burden of Disease (GBD) dataset

\subsection{Pollution}

The data on overall air pollution levels highlight strong differences in the initial conditions in 1990 as well as in the evolution over the last two decades. The least polluted countries are represented in blue (with darker blue shades highlighting the cleanest environment) whereas the most polluted countries are represented in red (with darker red for countries where the concentration of air pollution is high). The most polluted regions were Western and Eastern Europe, together with many emerging economies including many in MENA, as well as East and 
South Asia. Declines in air pollution occurred mainly in Western and Eastern Europe and to a lesser extent in North America, Saudi Arabia and a few countries in Sub Saharan Africa.

Figure 6: Air pollution (1990) and change in air pollution (1990-2010)

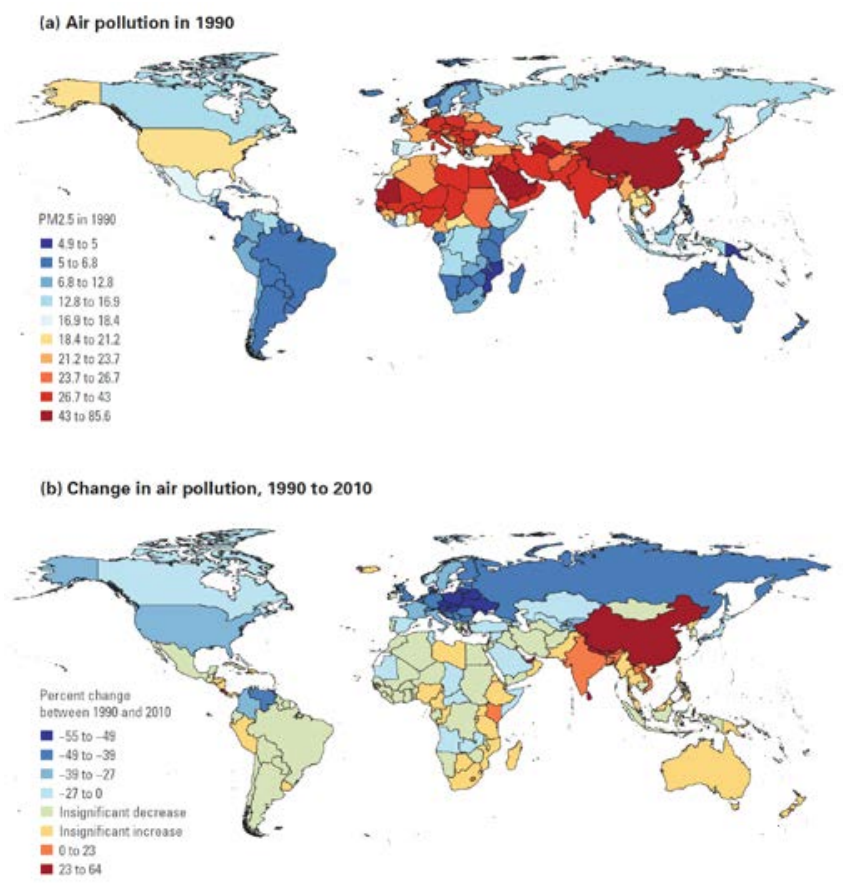

Source: Global Road Safety, World Bank and Institute for Health Metrics and Evaluation (2014)

Although it is hard to link the currently available epidemiological information with the pollution coming from vehicles, it is interesting to compare trends in the evolution of motor vehicle ownership. Vehicle ownership changes over the past few decades also point to significant increases in many emerging economies in East and South Asia as well as in Sub-Saharan Africa and a few countries in the Middle East, including Egypt and Morocco.

Figure 7: Evolution of vehicle ownership (1990-2010)

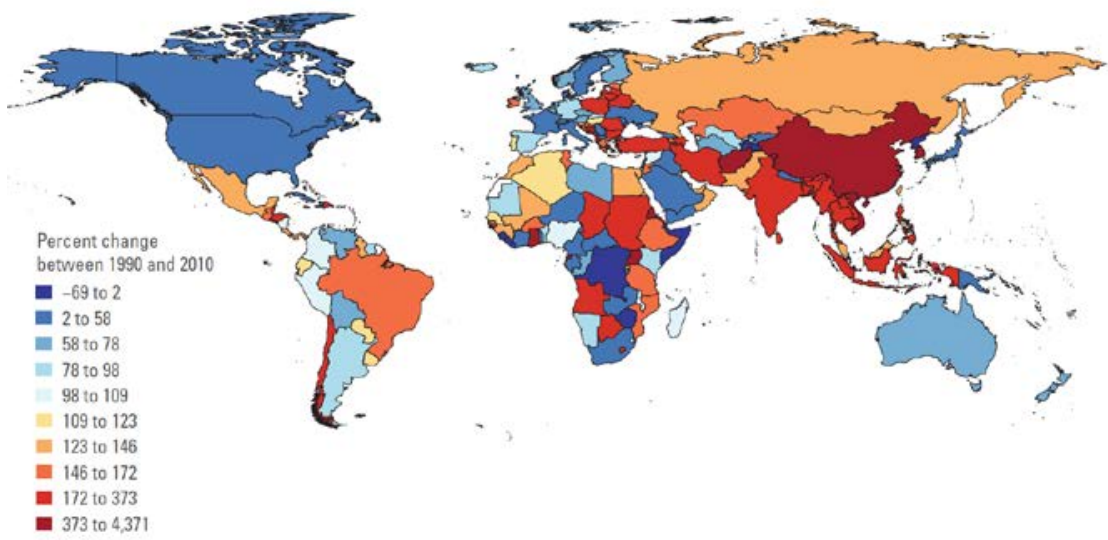

Source: Global Road Safety, World Bank and Institute for Health Metrics and Evaluation (2014) 
The data also suggest that countries with lower transport fuel prices are characterized by a much higher consumption of fuels for road transportation in lower-middle income countries. The link does not extend to higher-middle and high-income countries, probably due to the advanced level of vehicle ownership per capita.

Figure 8: Difference in road fuel (diesel/gasoline) consumption for countries with above and below average fuel prices

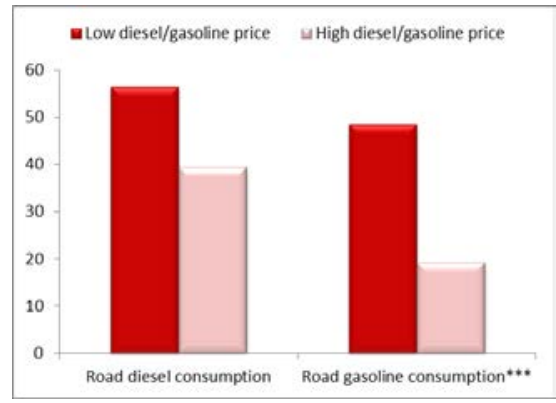

Source: Authors' elaboration based on WDI dataset

Note: *** denote significance of t-test between the average groups at $1 \%$ confidence level

Health losses due to vehicle air pollution are very high in the MENA region, close to OECD high-income countries (with the exception of the EU countries). The evidence also suggests that countries with higher motor vehicles per capita are characterized by a much higher toll in terms of deaths due to air pollution.

Figure 9: Motor vehicle air pollution deaths (per 100,000 people) by region and difference in death air pollution rates for countries with above and below average fuel prices

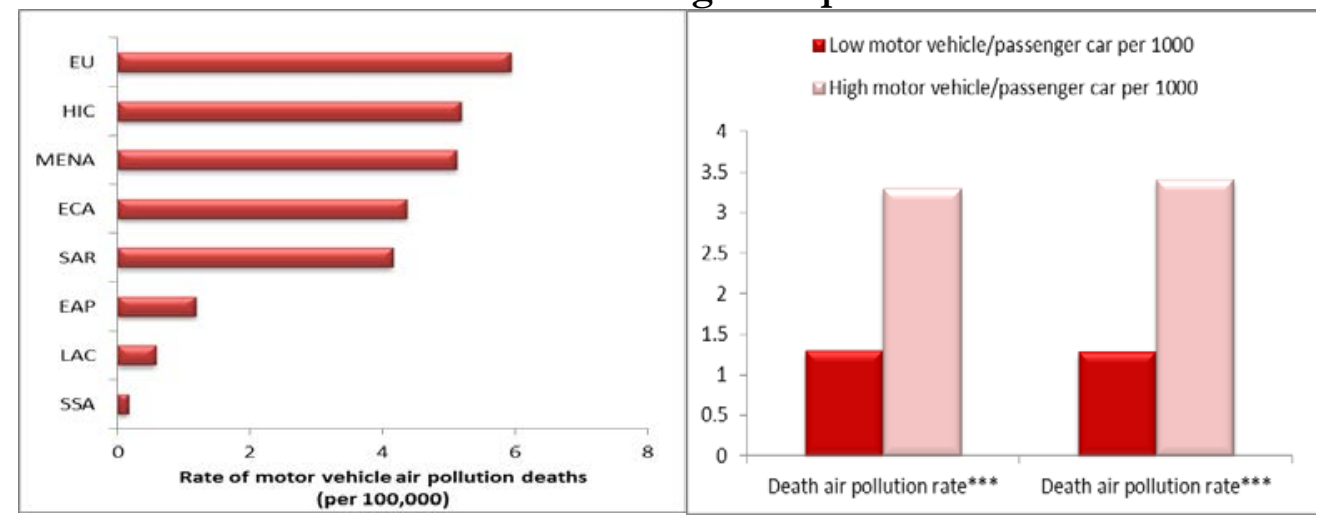

Source: Authors' elaboration based on Institute for Health Metrics and Evaluation's Global Burden of Disease (GBD) and WDI dataset

Note: $* * *$ denote significance of t-test between the average groups at $1 \%$ confidence level

Putting these elements together, it appears that road transport is a leading risk factor for premature death and disability in the MENA region. The importance of road injuries and air pollution as a risk factor for health depends on its relative ranking among other risk factors for premature death and disability. The figure below ranks the leading risk factors according to their contribution to disease burden in each region. The years of life lost due to premature mortality rank among the ten most risky factors (higher than in South Asia and Sub Saharan Africa). 
Figure 10: Ranking of health loss due to road transport injuries and air pollution compared with leading risk factors

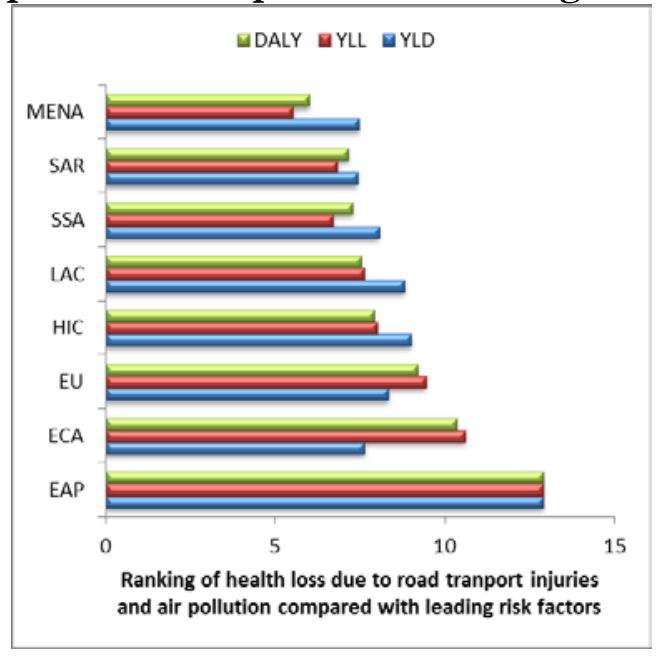

Source: Authors' elaboration based on Institute for Health Metrics and Evaluation's Global Burden of Disease (GBD) dataset

The evidence also suggests that countries with lower transport fuel prices are characterized by a much higher toll rate. However, the link between low transport fuel pricing and transport as a risk factor for disability is not significant, which points to other factors including changes in vehicle ownership being more strongly related.

Figure 11: Difference in ranking of health loss due to road transport injuries and air pollution compared with leading risk factors

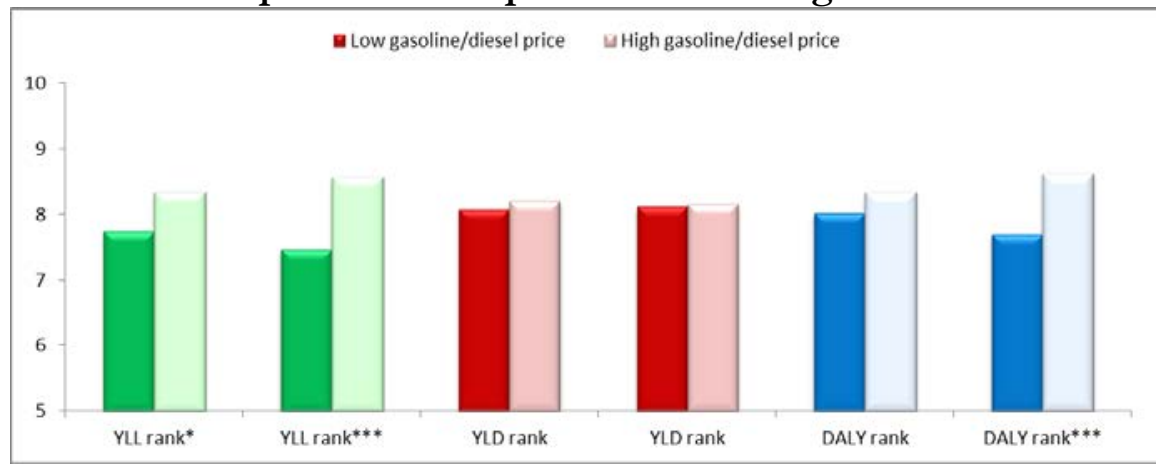

Note: $* * *$ denote significance of $\mathrm{t}$-test between the average groups at $1 \%$ confidence level $*$ denote significance of $\mathrm{t}$-test between the average groups at $10 \%$ confidence level

Source: Authors' elaboration based on Institute for Health Metrics and Evaluation's Global Burden of Disease (GBD) and WDI dataset

\section{Fuel pricing in the Egyptian context}

Energy subsidies have long represented a substantial fiscal outlay. Although, the budget for FY2013/2014 targeted around LE 100 billion for energy subsidies - a significant drop from LE 120 billion in 2013 - it is not clear how such savings are to be realised. As such, total spending on energy subsidies was likely to remain in the range of $8-10 \%$ of GDP. 
Figure 12: Egypt energy subsidies (by fuel), Fiscal year 2005/2006-2012/2013

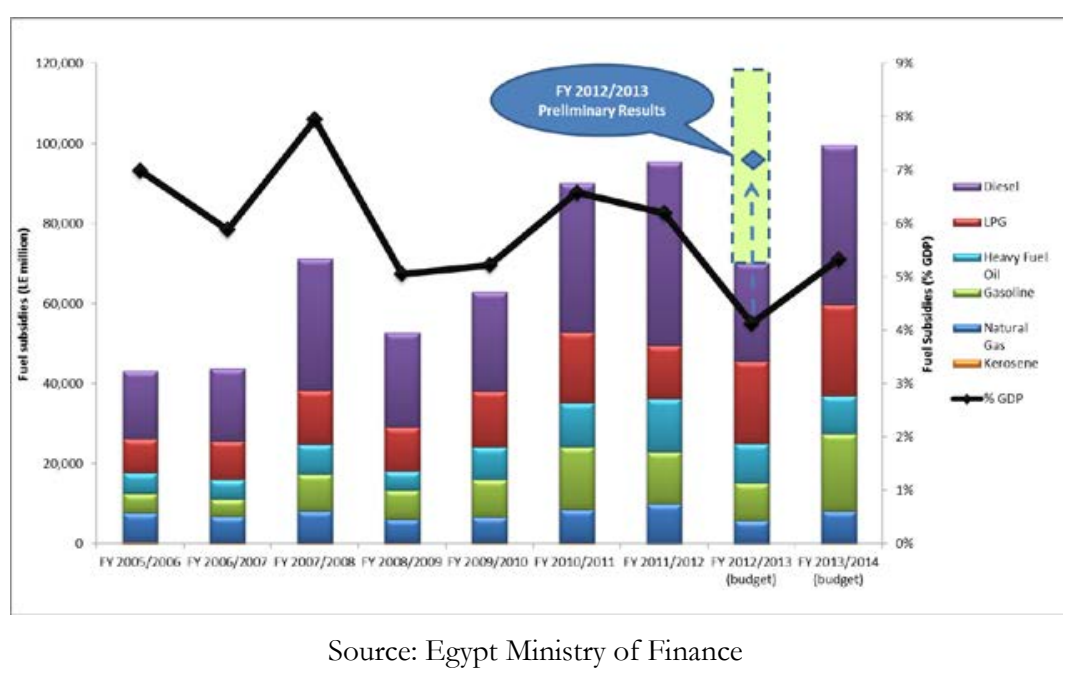

Petroleum subsidies have represented on average above $6 \%$ of GDP and are the largest component of budgetary subsidies. Among fuels, the lion's share of the fuel subsidy (on average $>40 \%$ ) is accounted for by light fuel oil (solar) followed by Liquefied Petroleum Gas (LPG), whose share has averaged around $20 \%$. The rest is divided almost equally across natural gas, gasoline, and heavy fuel oil. It is also well documented that energy subsidies are highly regressive and are largely to the benefit of the upper income groups.

Fuel consumption varies substantially across household and industries. A third of total gasoline and oil consumption comes from the transport and communication sector, followed by tourism, construction and energy intensive industries. LPG is almost entirely consumed by households while over $90 \%$ of natural gas consumption is used to generate electricity. More than $60 \%$ of the total consumption of fuel oil (mazout) is accounted for by electricity with the rest being used by households and energy intensive industries.

Figure 13: Egypt energy subsidies (by fuel and sector)

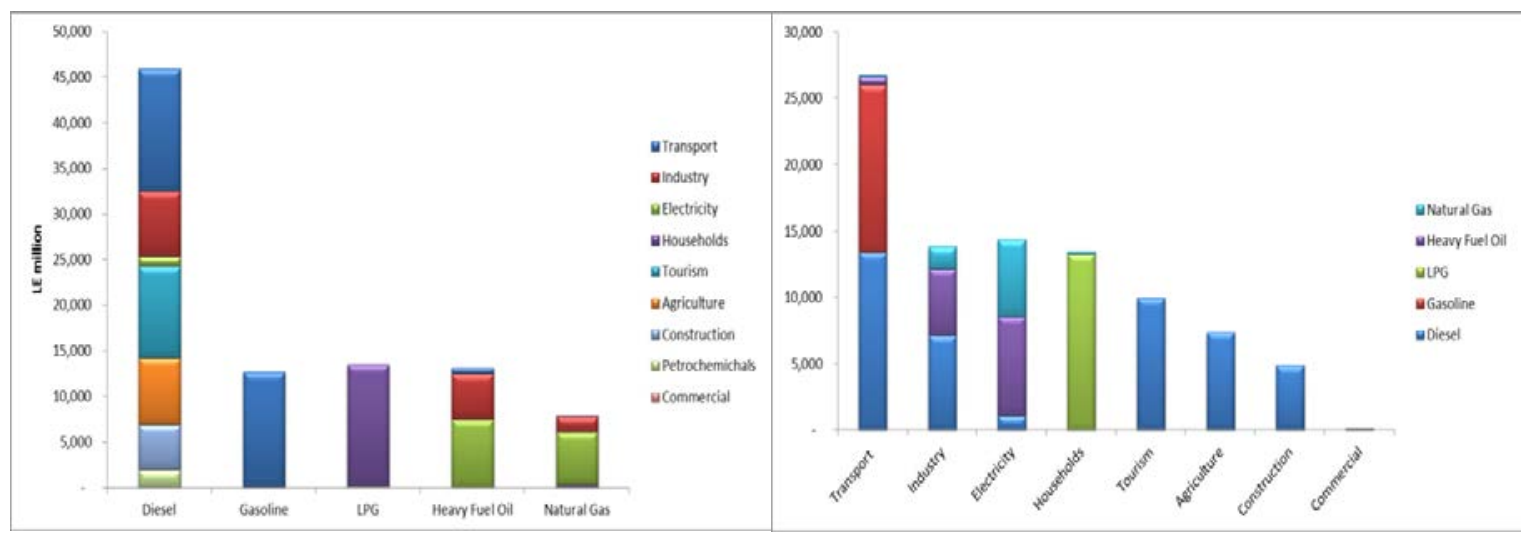

Source: Egypt Ministry of Finance

Subsidies to consumption, by lowering end-use prices, encourage increased energy use and reduce incentives to conserve energy and use transport efficiently. Excessive energy use is also 
associated with local pollution and congestion costs, notably by subsidising the cost of private automobile or truck use.

\subsection{Measuring Congestion in Cairo}

The World Bank's Cairo Congestion Study (2010) has estimated the cost of congestion for the Greater Cairo area using data on 11 major corridors in the city. The study uses the following indicators: (a) cost of travel time delay imposed on users (passengers as well as freight). The study estimates these costs to be in the region of 2.4 to 2.6 billion Egyptian pounds (LE), (b) the cost of travel time unreliability in passenger transportation - estimated at 1.7 billion LE for passenger and 13.5 million LE for freight transport, (c) cost of excess fuel consumption in vehicular transportation (diesel and gasoline) - estimated at $2.38-2.85$ billion LE and, (d) the associated cost of Carbon Dioxide (Co2) emissions due to excess fuel consumption - 86 - 97 million LE. The total direct traffic congestion cost for these 11 corridors is consequently estimated to be in the range of $6.6-7.0$ billion LE, which was equivalent to around $0.6 \%$ of 2010 Egyptian GDP.

The study also attempted some more complex estimates to derive volume to capacity ratios for the entire transport network. Total annual direct congestion costs were estimated to be in the range of 13 - 14 billion LE or around 1.2\% of GDP. The highest shares in total direct costs were travel time delays $(36 \%)$ and excess fuel cost $(37 \%)$, of which half was paid by users and half was attributed as additional costs to the Government on account of fuel subsidies. These were followed by unreliability costs $(25 \%)$ and, finally, Co2 emissions costs amounting to less than $1 \%$ of total costs.

\subsection{Measuring pollution in Cairo}

In similar vein to the congestion study, the World Bank (2009) has also produced a pollution study that estimates the impact of pollution on the Greater Cairo region using the DALY measure. According to the study, the total DALY lost to mortality and morbidity as a result of pollution was roughly 164,124. Scaling this by GDP per capita and dividing through by GDP for 2009 gives a rough estimate of 0.2 per cent of GDP. The study (2009) also provides other estimates of the levels of pollution for 2008/2009, such as PM10, PM2.5 and Pb. These will allow us in future (see below) to make the link to changes in DALYs. A recent assessment of comparative levels of pollution places Egypt as the MENA country most affected by road vehicle air pollution deaths in per capita terms, more than twice the rate in Lebanon, which ranks second and more than 100 times the lowest rate. 
Figure 14: Rate of motor vehicle air pollution deaths

(absolute number and per 10,000 people)

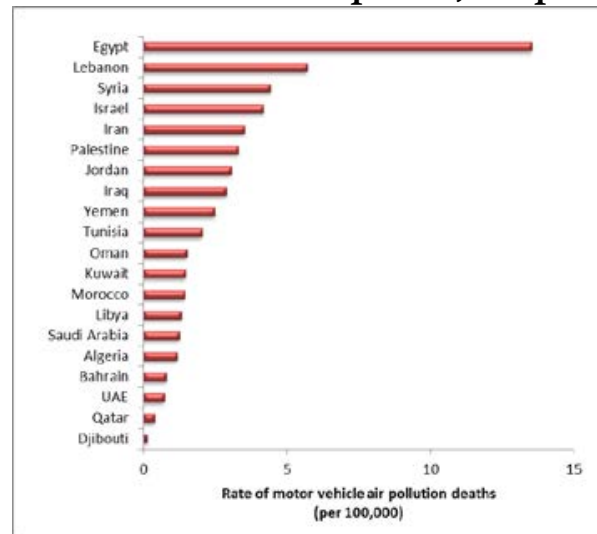

Source: Authors' elaboration based on Institute for Health Metrics and Evaluation's Global Burden of Disease (GBD) dataset

\subsection{Modal competition}

The dominance of road transport using private cars and motorcycles emerges strongly from the data below which show that they represent $>70 \%$ of the vehicle fleet in Egypt. The annual rate of growth is also striking, amounting to an average of $10 \%$ in the case of private cars and $20 \%$ for motorcycles.

Figure 15: Egypt vehicle fleet, by year (number and percentage)

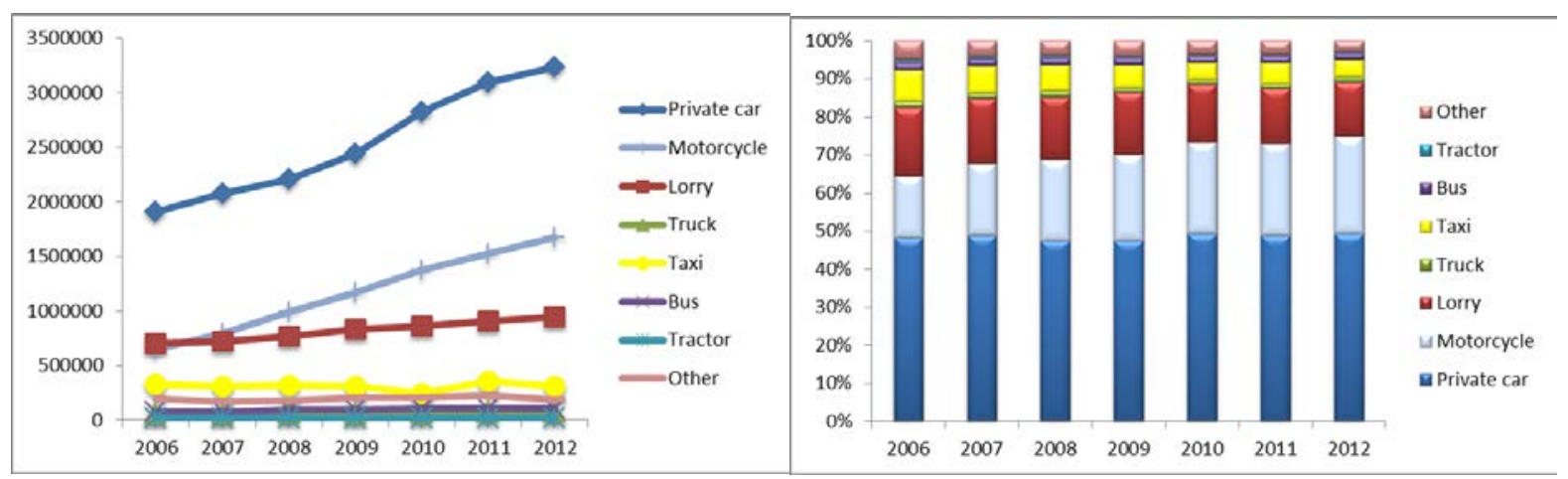

Source: Egypt Ministry of Transport

Official statistics indicate that there are almost 800,000 trucks in Egypt but about 70\% of them are small vehicles with a payload of less than 3 tons. Another 17\% are between 3-8 tons and also unsuitable for inter-urban freight. That leaves less than 100,000 trucks of more than 8 tons net weight that could be used for inter-urban freight, and of these only about 70,000 are semi-trailers or truck trailers with a payload that makes them suitable for efficient inter-urban freight transport. In short, the current structure of the trucking industry does not respond to the needs of its clients, but at the same time it appears that there is an unwillingness to pay the higher cost that more reliable trucking services would require. The low tariffs of the current operators have in turn been associated with chronic overloading and a high accident rate. 
More generally, it appears that there is a lack of effective alternatives in terms of intermodal competition for both passengers and freight transport. By 2012, railways in terms of freight and passengers transported were at levels lower than in the early 1990s. The rate of decline in railway transport in the last six years has been substantial, amounting to an average of more than 13\% for freight and just below $10 \%$ for passengers. The quality of the railways as a mode of transport has been assessed as poor by about $80 \%$ of users.

Figure 16: Egypt railway freight and passengers, by year and perception of quality and price of infrastructure, 2012

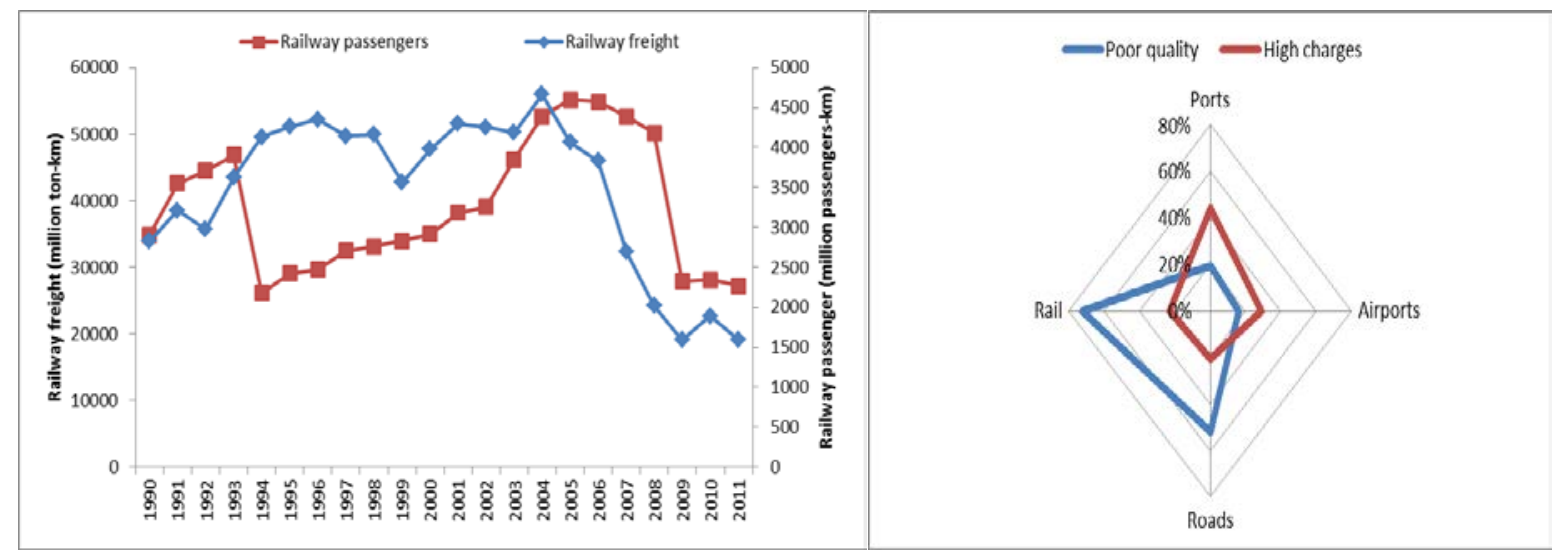

Source: Egypt Ministry of Transport for the data on railway passenger and freight and World Bank Logistic Performance Index for the data on perception of quality and price of the transport infrastructure

Transport by road has also led to a substantial increase in fuel consumption for the sector even though its intensity (as a share of GDP) has been declining over time.

Figure 17: Egypt road sector fuel consumption and intensity, by year

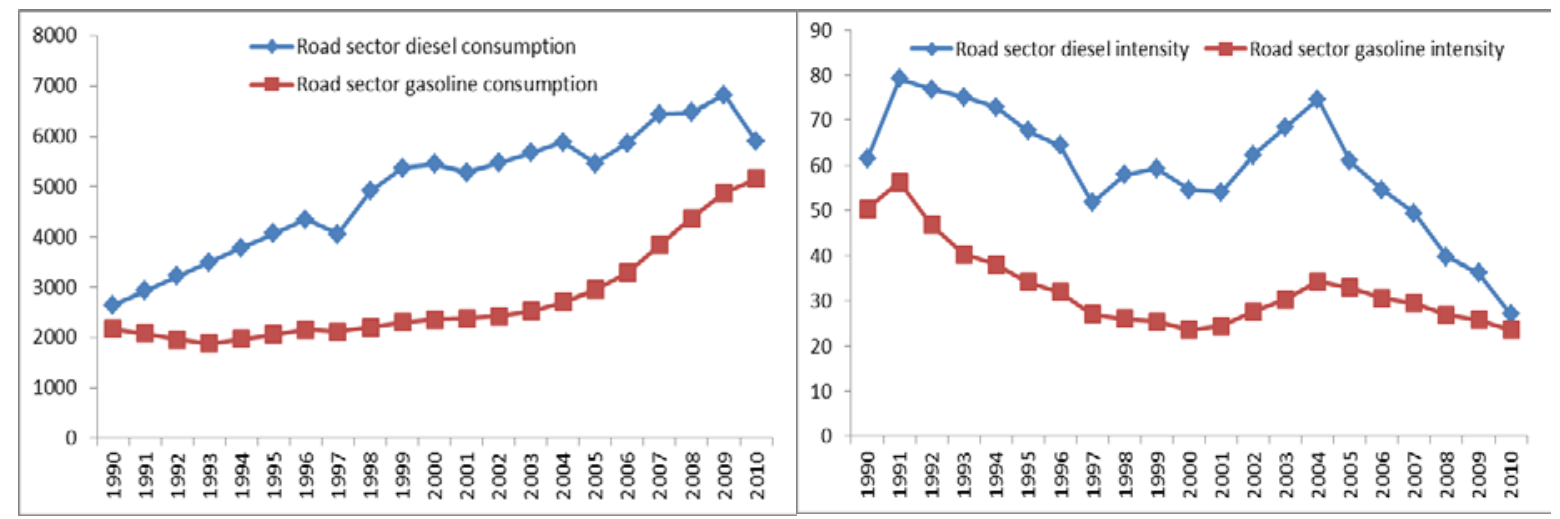

Source: Egypt Ministry of Transport

\subsection{The water-energy nexus in MENA and the social cost of water depletion}

The availability of renewable water resources in the MENA region is about 500 cubic meters per capita per annum, making the degree of water scarcity the highest in the world. Availability of renewable water is 15 to 70 times higher in ECA and LAC respectively. Renewable water 
resource availability is as low $<30$ cubic meters per capita per annum in Kuwait, UAE and Qatar, followed by Yemen. Only a few countries in MENA - such as Iraq, Iran and Lebanon - have more than 1,000 cubic meters per capita.

Figure 18: Renewable water resource availability ( $\mathrm{m} 3 /$ per inhabitant/year) by region and for MENA countries

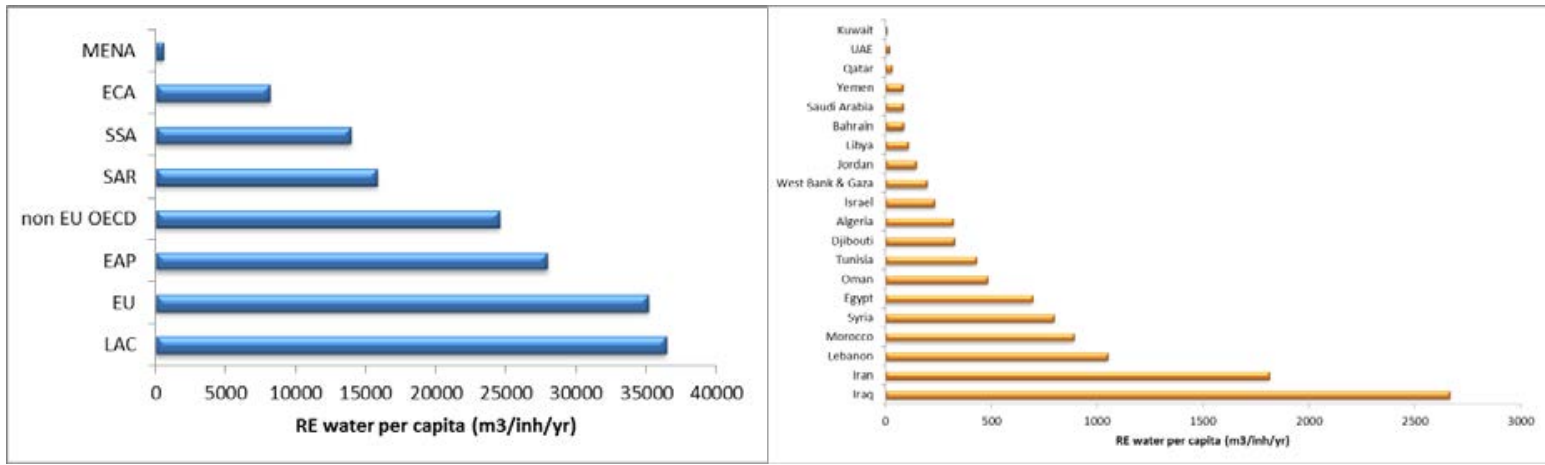

Source: Authors' elaboration based on Aquastat's database

Renewable water availability has also been declining over time, with a rate of decrease of $35 \%$ over the last decade. For some countries, the rate of decrease has been as high as $75 \%$, for example in UAE and Qatar.

Figure 19: Water depletion (\% decrease in water resources) by region and for MENA countries

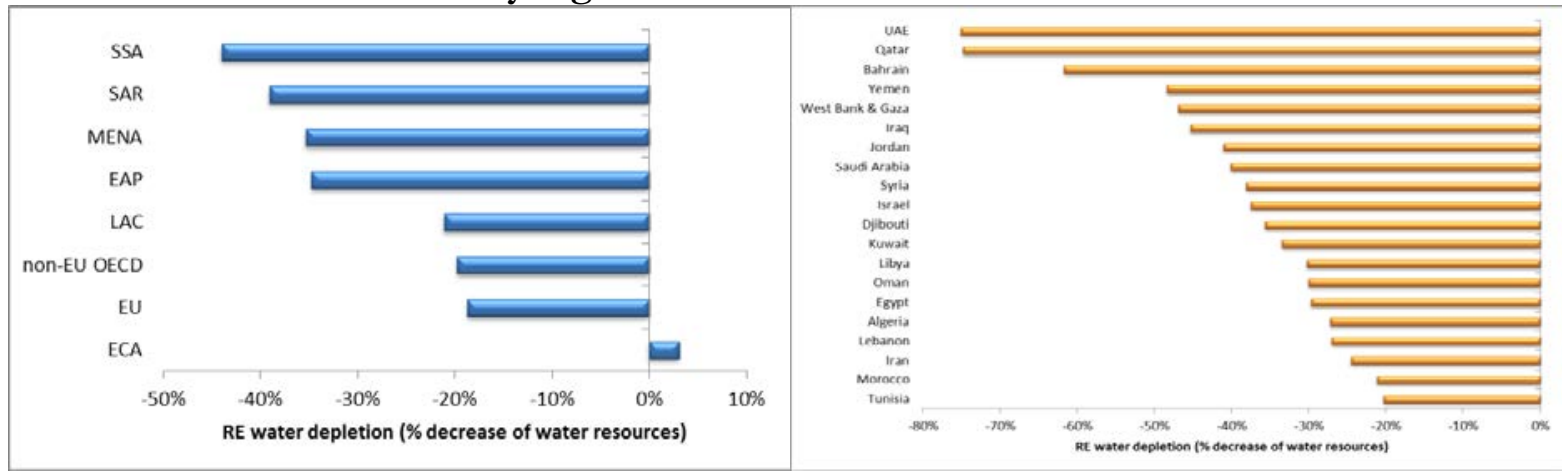

Source: Authors' elaboration based on Aquastat's database

Withdrawal to availability ratios are also highest in MENA, amounting on average to just below $400 \%$. In other regions they range from 6 to 54\%. Countries such as Egypt and Jordan are reaching the 100 per cent threshold. Lebanon, Morocco and Algeria are the only countries where water withdrawal is less than 50 per cent. 
Figure 20: Water withdrawal (\% renewable water resources) by region and for MENA countries

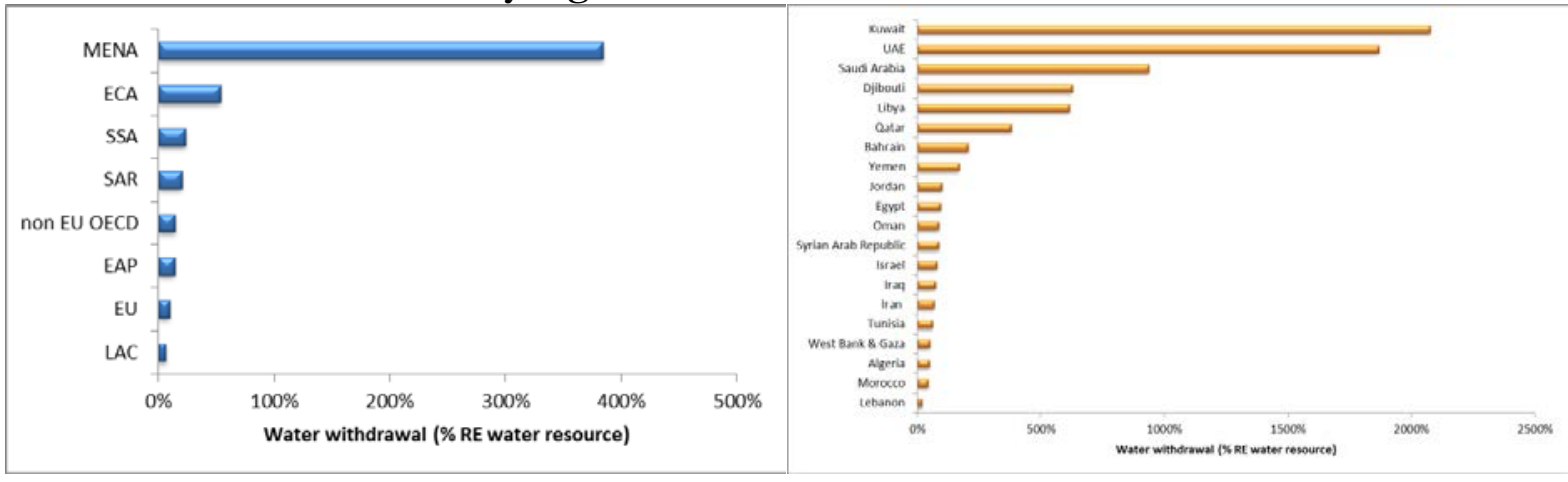

Source: Authors' elaboration based on Aquastat's database

The evidence also suggests that countries with lower than average diesel prices are characterized by much higher (and statistically significant) water depletion than those that have increased diesel prices. MENA countries with below average diesel prices seem to be characterized by far higher water depletion rates. Although, it is not possible to impute direct causality, it would appear that fuel pricing may play a role in driving the extent of resource depletion and this will be a central conjecture that we will be examining.

Figure 21: Difference in water withdrawal (\% renewable water resources) for countries with above and below average fuel prices

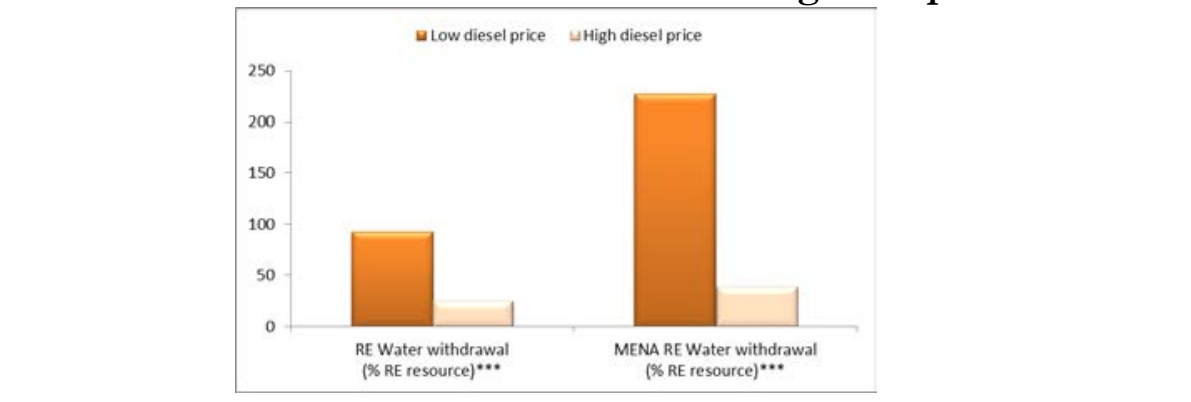

Note: $* * *$ denote significance of t-test between the average groups at $1 \%$ confidence level

Source: Authors' elaboration based on Aquastat's database

The highest - and rather specific - source of withdrawal is represented by fresh groundwater. For the majority of MENA countries groundwater withdrawal is higher than 50 per cent. Desalinated water represents also a significant source of water withdrawal.

Coping with increasing water scarcity and groundwater depletion - such as pumping of water across large distances and the use of desalination - requires high energy consumption. Indeed, water abstraction, purification (desalination) and wastewater treatment represent some of the most energy intensive activities employed in the region. Similarly, lifting water from the ground requires more energy than using gravity-based conveyance of surface water. At present, pumping for irrigation and drainage consumes around $6 \%$ of total electricity and diesel in MENA. In principle, pumping efficiency improvements could lead to significant energy savings, possibly as much as $10,000 \mathrm{GWh}$ electrical power per annum. 
In the case of GCC countries a significant percentage of total electricity consumption may be from desalination alone. In the case of UAE more than 20 per cent of energy is used for desalinization and in Algeria and Qatar more than 10 per cent. In the case of Saudi Arabia low end estimates point at 5 per cent of electricity consumption used for groundwater pumping and 4 per cent for desalinization. Egypt produces and treats the largest amount of wastewater from industrial and municipal sources. As a consequence, Egypt estimated energy consumption for wastewater treatment could represent about $1 \%$ of total electricity consumption.

Figure 22: Composition of source of water withdrawal (\%) by region and MENA countries

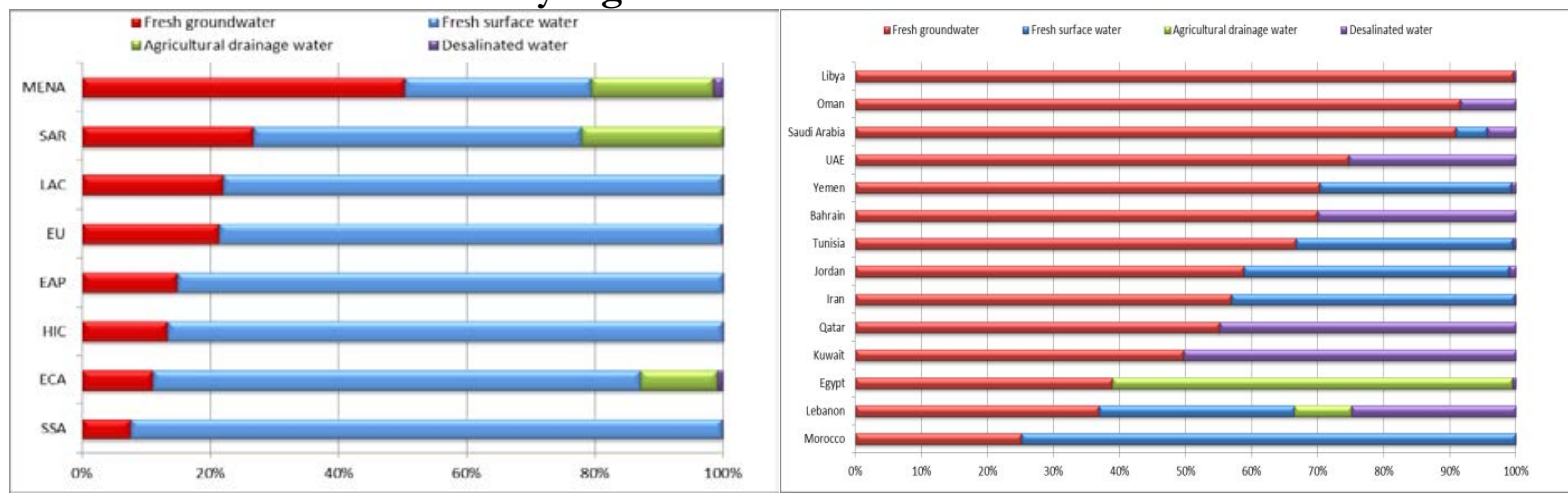

Source: Authors' elaboration based on Aquastat's database

Most water use is concentrated in agriculture and the sector exhibits relatively low value added activity both compared to other sectors in the same country as also with respect to agriculture in other countries.

Figure 23: Decomposition of water use by sectors (\%) by region and MENA countries

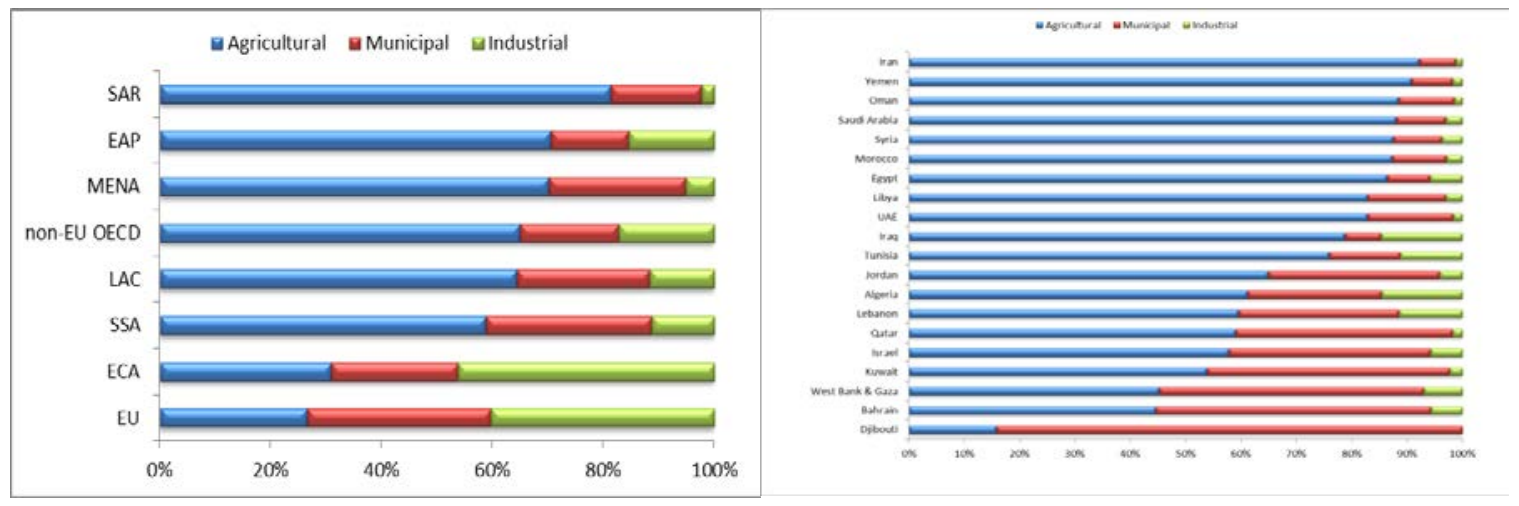

Source: Authors' elaboration based on Aquastat's database

The evidence suggests that countries with lower than average diesel prices are characterized by much higher (and statistically significant) agricultural water withdrawal than those that have increased diesel prices above average. The between group difference is slightly higher in MENA countries but less significant. 
Figure 24: Difference in agriculture water withdrawal (\% renewable water resources) for countries with above and below average fuel prices

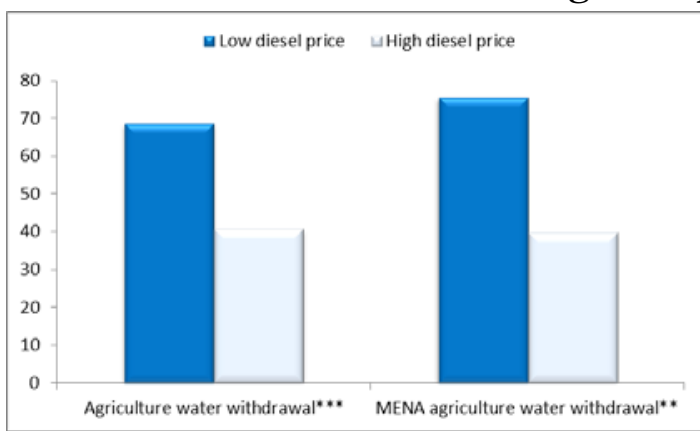

Note: $* * *$ denote significance of $\mathrm{t}$-test between the average groups at $1 \%$ confidence level $* *$ denote significance of $\mathrm{t}$-test between the average groups at $5 \%$ confidence level

Source: Authors' elaboration based on Aquastat's database

Interestingly for our purposes, the countries relying on groundwater withdrawal for irrigation is also among the highest in the world with the irrigated area approximating 65 per cent as against less than 10 per cent in East Asia or Sub-Saharan Africa. Most of the Gulf countries and Yemen rely entirely on groundwater withdrawal for irrigation.

Figure 25: Decomposition of water use by sectors (\%) by region and MENA countries

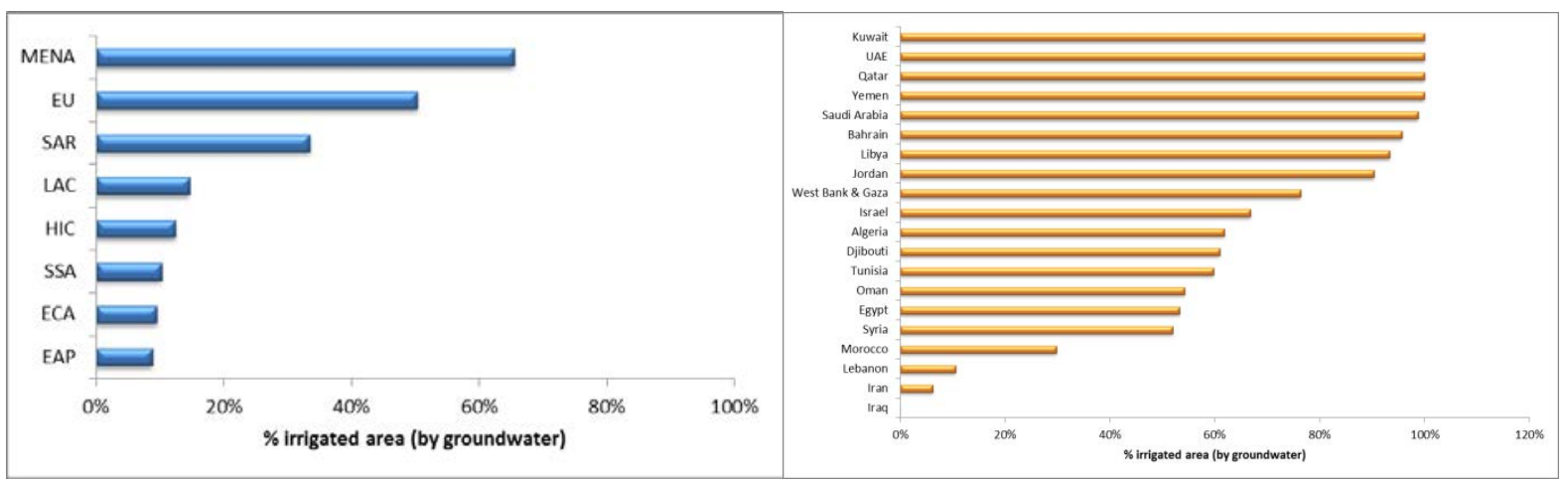

Source: Authors' elaboration based on Aquastat's database

The harvested irrigated crop area as a proportion of area equipped for full control irrigation is close to 100 per cent on average with percentages even higher in countries such as Yemen, Jordan and Egypt. 

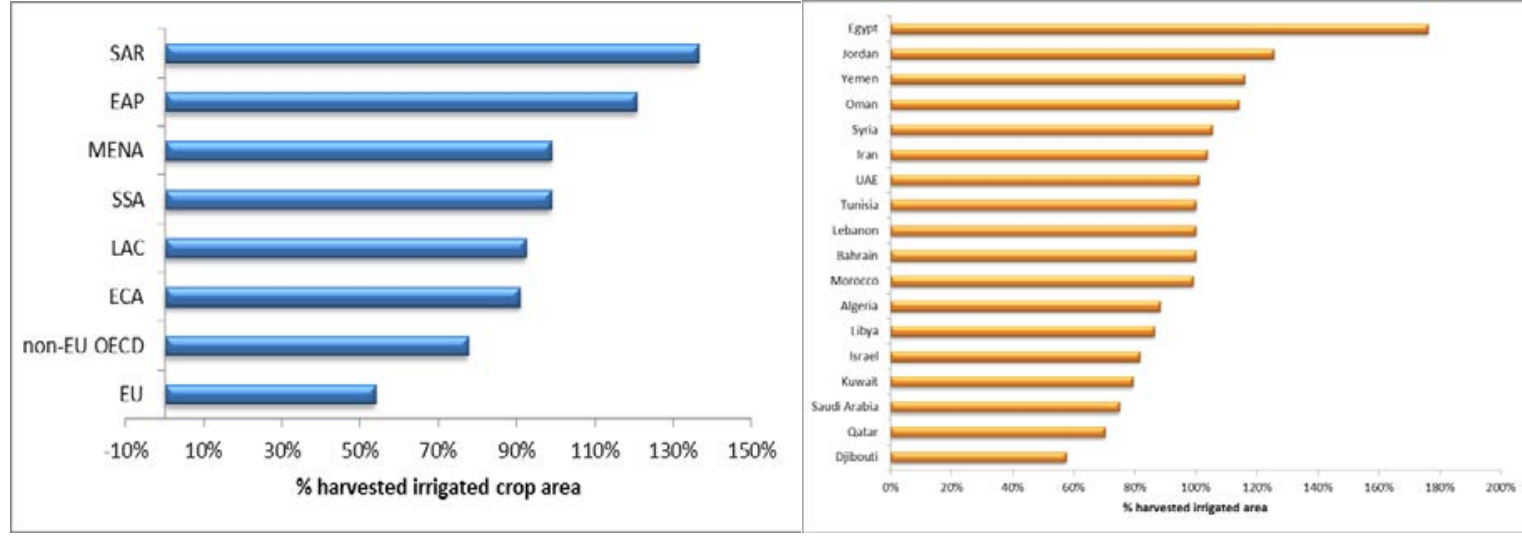

Source: Authors' elaboration based on Aquastat's database

The evidence suggests that countries with lower than average diesel prices are characterized by much higher (and statistically significant) harvested irrigated crop area and irrigation water requirements than those that have increased diesel prices. The between group difference is slightly higher in MENA countries in terms of harvested irrigated crop areas, but is much higher in terms of irrigation water requirement per capita, pointing at the wasteful use of water for irrigation due to low price signals. Again, we need to be careful about suggesting causality.

Figure 27: Difference in harvested irrigated crop areas and irrigation water requirement per capita globally and for MENA region for countries with above and below average fuel prices

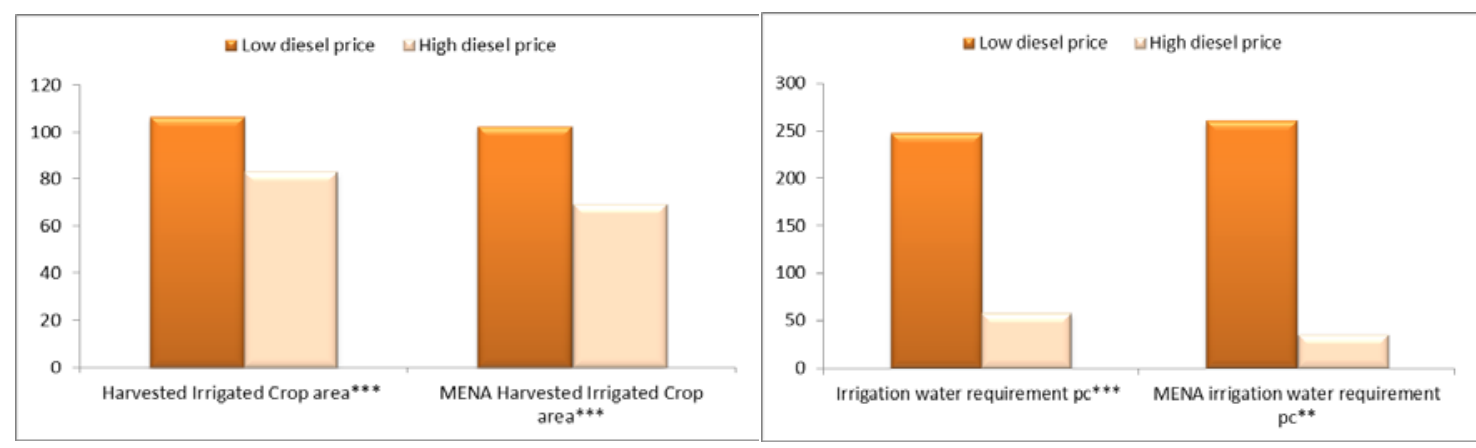

Note: *** denote significance of t-test between the average groups at $1 \%$ confidence level $* *$ denote significance of t-test between the average groups at $5 \%$ confidence level

Source: Authors' elaboration based on Aquastat's database

What is clear, however, is that greater efficiency of water use can have a significant impact on energy consumption. Raising the effective price for pumping can reduce the incentive for irrigating and, in some circumstances, have an impact on trading patterns, to the extent that countries switch out of water intensive crops, relying on imports instead. Importing water intensive crops could be associated with water and energy savings, as well as lower rates of resource depletion from aquifers. 
A study of Syria (Gul et al., 2005) showed that although subsidised fuel had a significant positive impact on cereal production, it was also associated with intensive groundwater use and aquifer depletion in water-scarce areas. The intensity of groundwater use had been associated with the expansion in areas of high water-consuming crops. The study also suggested that higher fuel costs led farmers to shift production to crops with higher water-productivity. The study also emphasized that fuel subsidies directly contributed to low water productivity (gross margin per cubic metre), particularly cotton.

\subsection{The water-energy nexus: evidence for Yemen}

Energy subsidies in Yemen remain very high at around 9\% of GDP in 2013 with a peak of 14\% in 2008. Of the total fuel subsidy in 2013, about 63\% went to diesel, split equally between electricity -- which is mainly used for off-grid electricity generation by industrial, commercial, agricultural and residential consumers -- and diesel for other industries. Heavy fuel oil and gasoline account for about $30 \%$, and the remaining $10 \%$ of the subsidy is split mainly between liquefied petroleum gas (LPG) and kerosene.

As elsewhere, these generalized subsidies benefit mainly the rich-since they consume most fuel and electricity - and provide incentives for overconsumption, inefficiencies, and smuggling. Further, they exacerbate Yemen's environmental problems by lowering the cost of pumping scarce underground water. Consequently, in Yemen pumping for irrigation and drainage accounts for $28 \%$ of the total electricity and diesel consumption, a share much higher than the $6 \%$ average for the MENA region. Yet, Yemen is one of the most water scarce countries in the world with only about 120 cubic meters of renewable internal freshwater resources available per capita. Food imports now account for around $80 \%$ of cereal consumption. In 2000, Yemen used $10 \%$ of its export earnings to import food; by 2012 this had risen to $35 \%$.

Agriculture remains a key sector in the Yemeni economy and the main source of income - direct and indirect - for nearly three-quarters of the population while employing more than half of the labour force. Yet agricultural productivity is very low and faces severe resource constraints that limit the potential for productivity growth. The ground waters on which more than half of agricultural output now depends are almost fully exploited and reserves are being rapidly depleted.

Behind this depletion, lies specific crop selection. In particular, qat - a stimulant widely chewed by Yemenis - accounts for around $40 \%$ of total water resource use. While profitable at current relative prices, qat crowds out production of food crops or export crops, and its consumption creates both social and health problems. However, a recent World Bank study (2010) concluded that reducing the subsidy to diesel fuel was unlikely to reduce water extraction or extend the life of the aquifers significantly. It is possible that technological changes combined with changes in institutional arrangements and energy prices may be able to achieve more efficient and sustainable resource use. 


\section{Simulating the impact of fuel price changes on congestion in Cairo}

Preliminary to a more in-depth exploration of the external costs of fuel subsidies and as a simplified benchmark for quantifying the impact, we now apply a simple simulation exercise to look at the impact of a fuel price increase (i.e., a fall in subsidy) on the social cost of congestion in Cairo. The data for the baseline case are taken from the World Bank Congestion Study (2010) that estimated the social cost of congestion in 11 major corridors in Cairo ${ }^{4}$. The social costs of congestion in the study were divided into four major categories. These were; (i) the cost of travel time delay imposed on users; (ii) the cost of travel time unreliability (both for passenger and freight transport); (iii) the cost of excess fuel consumption and, (iv) CO2 emissions. The estimation of costs was done using two approaches - speed plots and volume-to-capacity. They yielded the following magnitudes;

- Speed plots approach: (a) cost of travel time delay- 2.6 billion Egyptian pounds (LE); (b) cost of travel time unreliability -1.71 billion LE; (c) cost of excess fuel consumption 2.85 billion LE; and (d) cost of CO2 emissions - 0.097 billion LE;

- Volume-to-capacity ratio approach: (a) cost of travel time delay- 2.4 billion LE; (b) cost of travel time unreliability -1.71 billion LE; (c) cost of excess fuel consumption -2.38 billion LE; and (d) cost of CO2 emissions - 0.086 billion LE;

The total social cost of congestion was estimated at roughly 7 billion LE, amounting to $0.6 \%$ of 2010 GDP.

In order to simulate the impact of a price change, we need to have some estimates of both short and long term elasticities of vehicle travel to changes in fuel prices. Table 1 summarizes the findings of the recent literature. It suggests that the average short run elasticity of vehicle travel is -0.1 , whilst the long run is -0.3 - parameters that will also be applied in the simulation exercise. However, it should be pointed out that these estimates are drawn from analysis of advanced economies and may not reflect well developing country values. In addition, we are making two strong assumptions. The first is that we assume that the elasticity of social cost of congestion is equivalent to the elasticity of vehicle travel. The second is that we assume that there is no switching across modes of transport. We report the result of $10 \%, 20 \%$ and $50 \%$ increases in price for both the short and long run.

Figures 28 and 29 illustrate the short run impact of a 10\%, 20\% and 50\% increase in fuel prices. As suggested by the elasticities mentioned above, a $50 \%$ increase in the price of fuel will lead to a roughly $5 \%$ decrease in the overall social cost of congestion, which translates into a monetary value of approximately 360 million LE.

Figures 30 and 31 illustrate the long run impact of a 10\%,20\% and 50\% increase in fuel prices. The long-run elasticities suggest that a $50 \%$ increase in the price of fuel will lead to a roughly $15 \%$ decrease in the overall social cost of congestion, translating into 1.089 billion LE which is approaching $0.09 \%$ of GDP.

\footnotetext{
${ }^{4}$ Note that the magnitudes for the Greater Cairo region are roughly twice as large.
} 
Table 1. Summary of vehicle travel price sensitivity studies

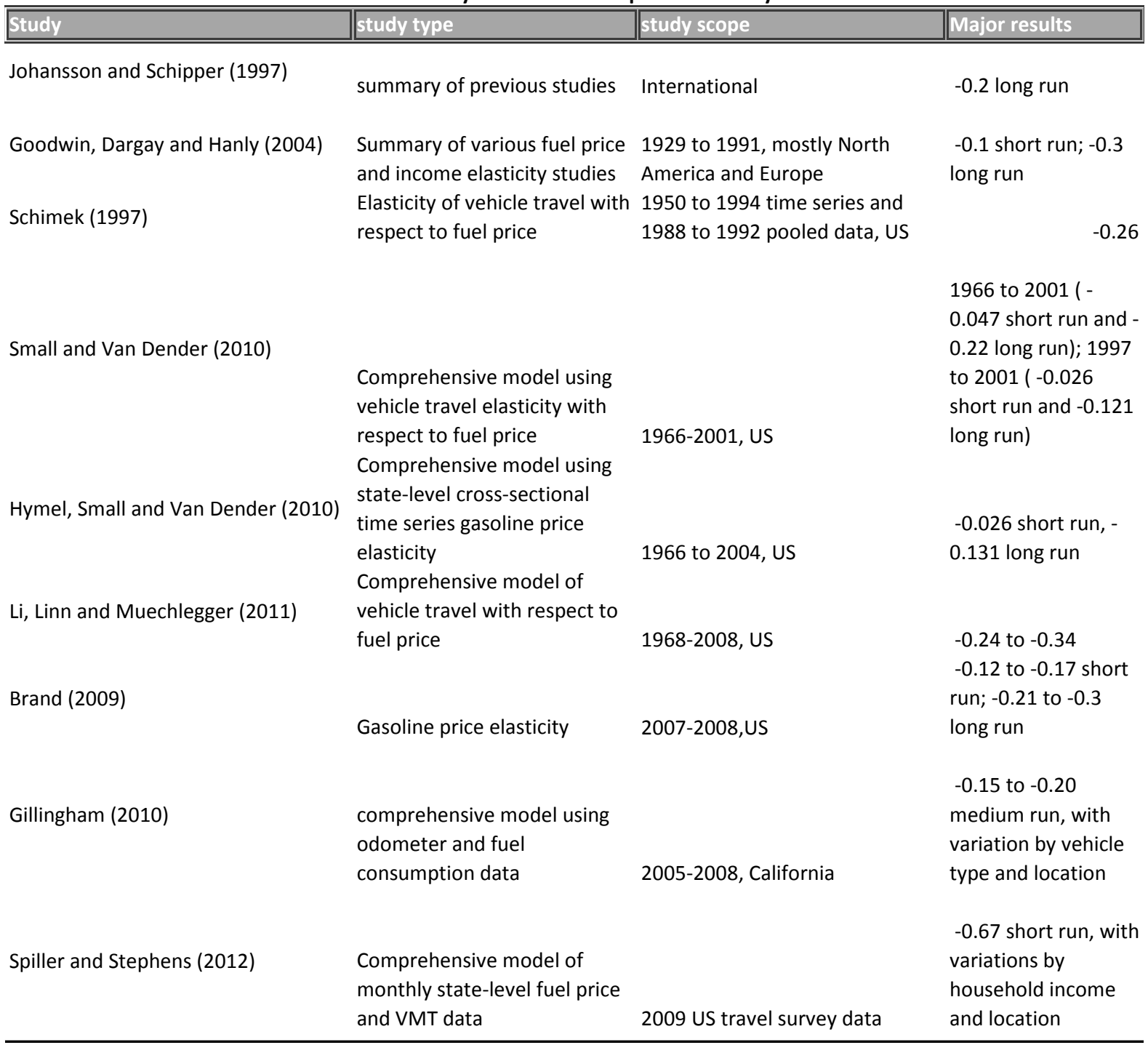


Figure 28: Speed plots approach - impact of short term price change on social costs of congestion (in billion LE)

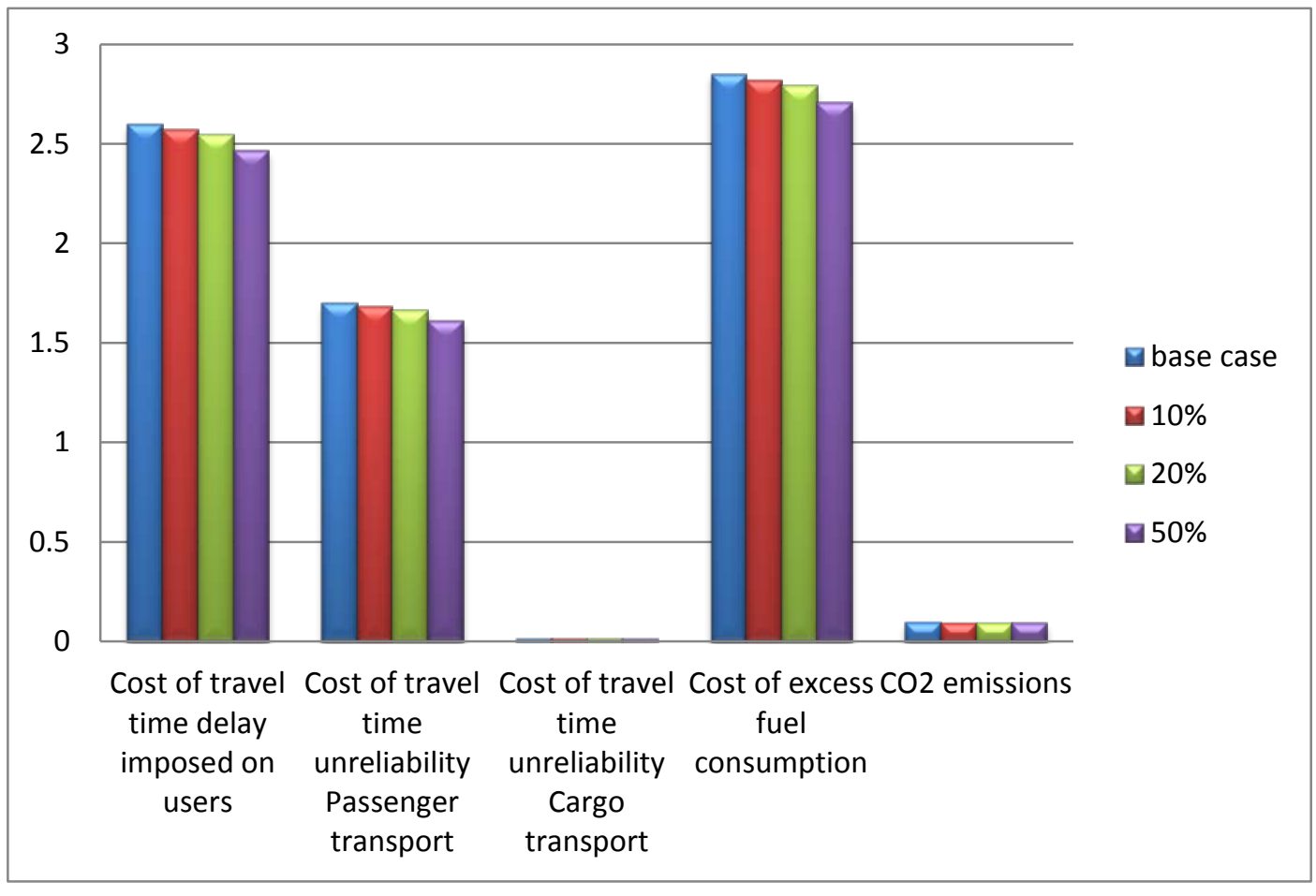

Source: Authors' elaboration based on World Bank (2010) and Litman (2012)

Figure 29: Volume to capacity ratio approach - impact of short term price change on social cost of congestion (in billion LE)

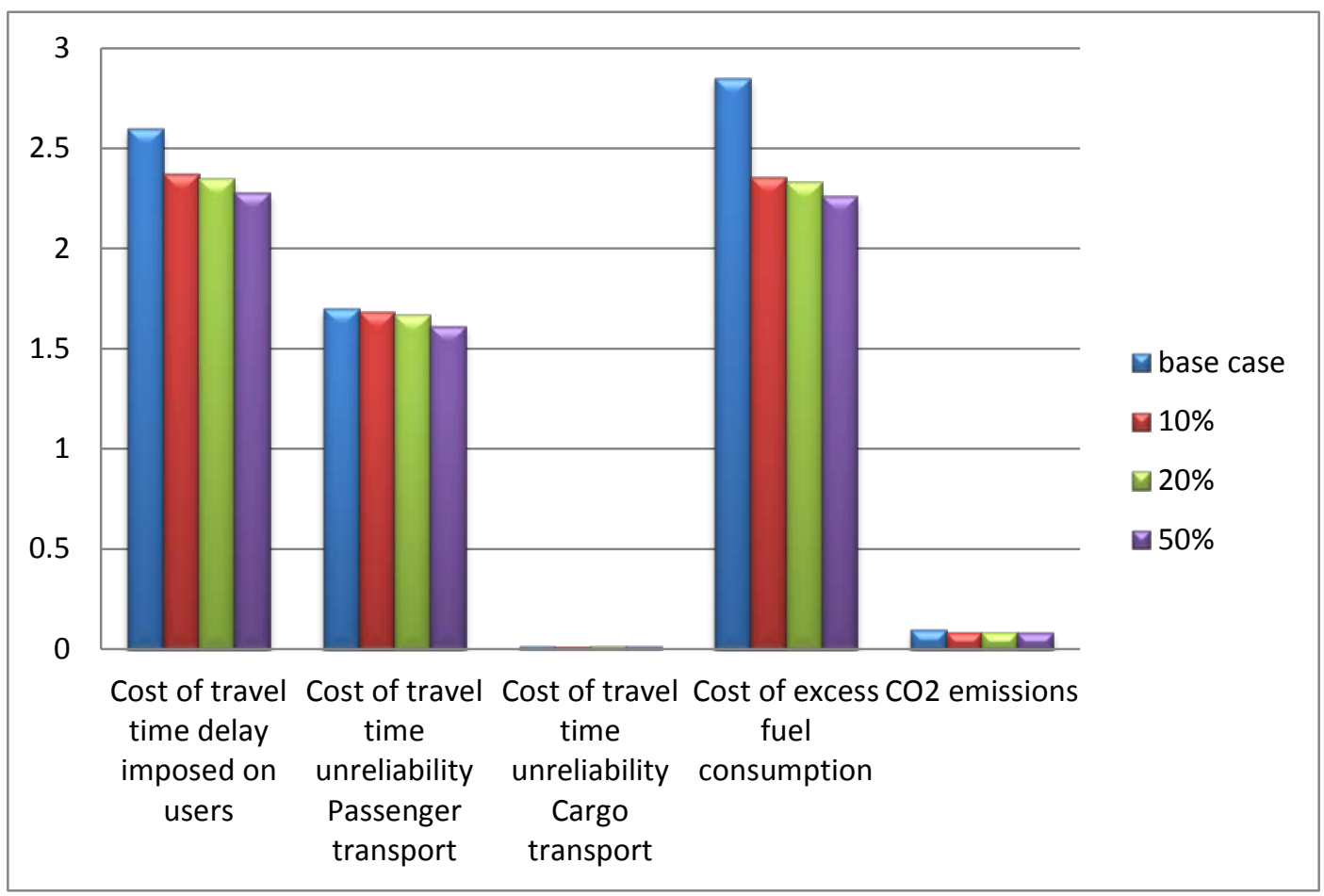

Source: Authors' elaboration based on World Bank (2010) and Litman (2012) 
Figure 30: Speed plots approach - impact of long term price change on social costs of congestion (in billion LE)

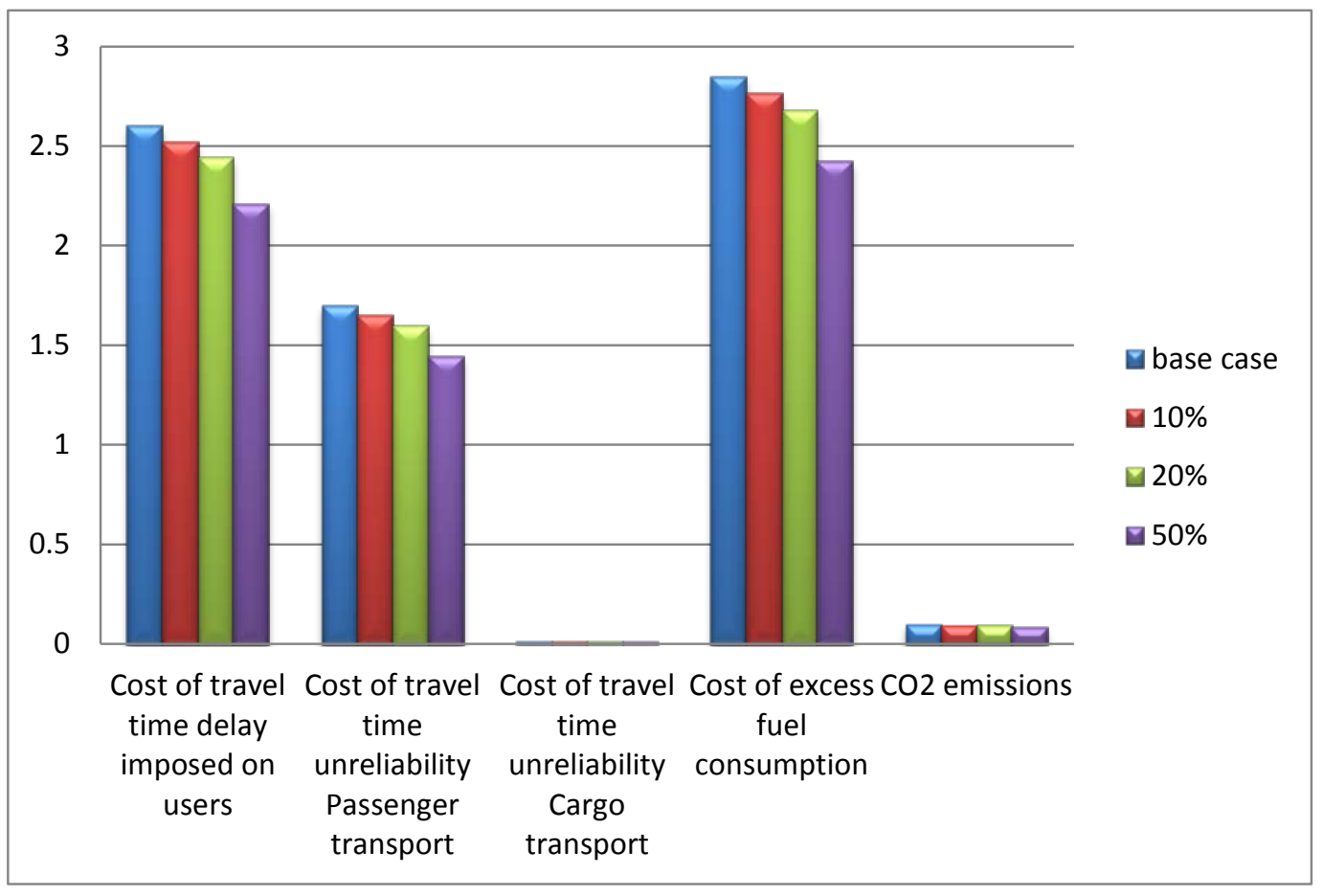

Source: Authors' elaboration based on World Bank (2010) and Litman (2012)

Figure 31: Volume to capacity ratio approach - impact of long term price change on social costs of congestion (in billion LE)

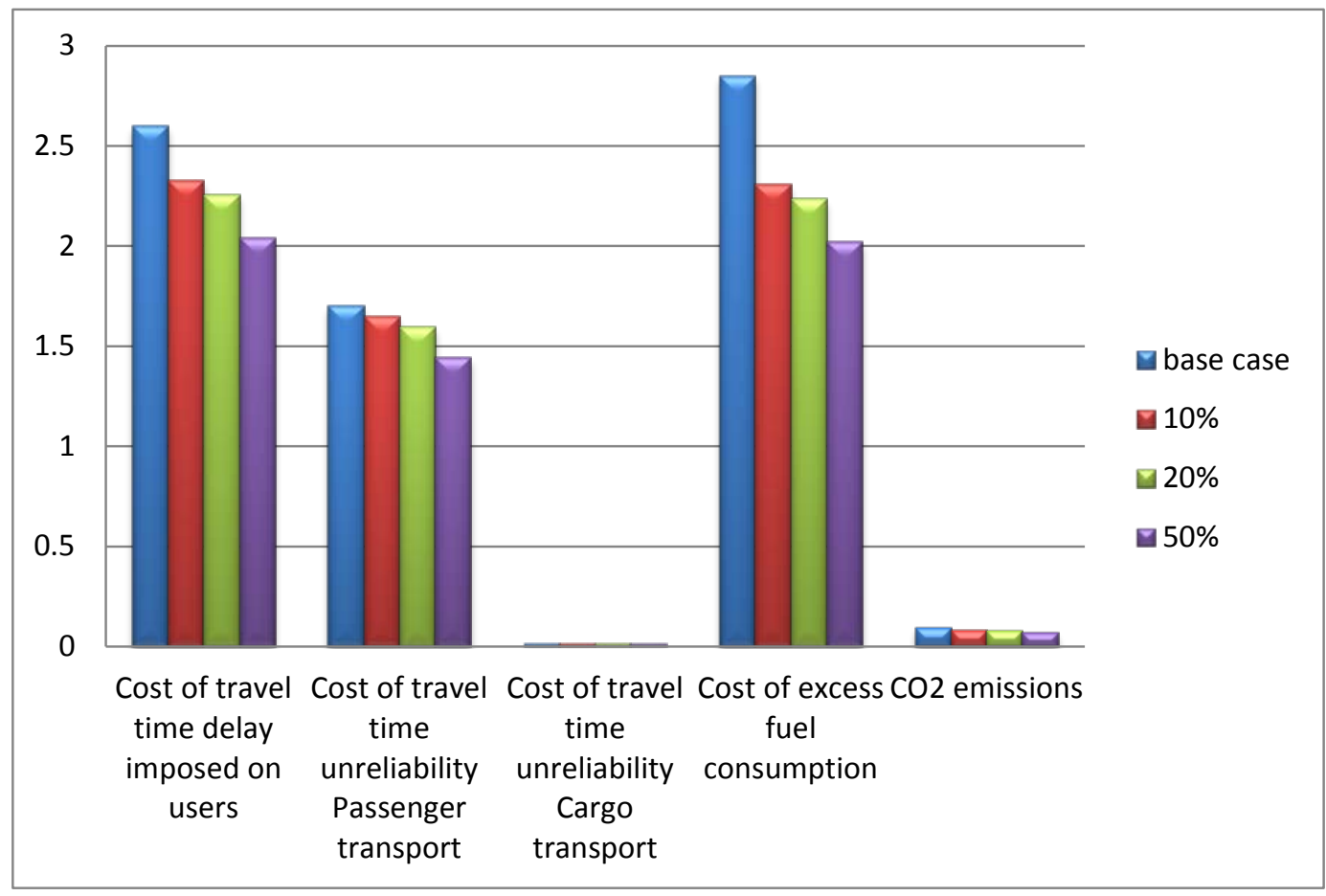

Source: Authors' elaboration based on World Bank (2010) and Litman (2012) 


\subsection{Linking emissions to health outcomes (DALYs)}

The simulations reported above give some sense of what happens to CO2 emissions and their cost. While there tends to be a relationship between CO2 and other pollution measures of relevance in a health or productivity context (such as PM10 and PM2.5), this is not mechanical. And it is these latter indicators that are used to make the link to health status.

At this point, we can retrieve some baseline data are from the World Bank Cairo Air Pollution study (2009). This estimates the total DALY (Disability Adjusted Life Years) due to pollution at 164,124. Dhont et al (2013) estimate the impact of a $20 \%$ increase in the price of fuel on the changes of DALY using data from Belgium. They find that a $20 \%$ increase in the price of fuel would be associated with a rough improvement of 1650 DALYs. If applied to the Egypt base estimate from WB (2009) this would correspond to a decrease in DALY of around 1 percentage point.

However, an important caveat is in order. The pollution particulates responsible for increased mortality/morbidity in Belgium are very much lower than in Cairo. For instance, PM10 and PM2.5 concentrations in Brussels are 26 and 18 milligrams per cubic metre - significantly lower than the PM10 and PM2.5 concentration in Cairo of 144 and 83 milligrams per cubic metre respectively. This suggests that the calculated $1 \%$ decrease in DALYs as a result of a price increase is a significant under-estimate.

\section{Modelling external effects in transport}

In this section, we now move to modelling external effects using a multi-year framework developed by the UN named ForFITS ${ }^{5}$. This model has two objectives. The first is the estimation of emissions in transport for a given transport stock and its composition and intensity of use. The second is the evaluation of transport policies for, in particular, mitigating CO2 emissions. The model also permits simulation of fuel price changes on transport activity. In an extension, we link CO2 emissions to those for particulates - as measured by PM10 - and then in a further step link to the impact on mortality and morbidity using the measure of DALYs.

The model evaluates transport activity expressed in units such as passenger kilometres (pkm) and vehicle kilometres (vkm), stocks of vehicle types, energy use and CO2 emissions. A range of possible policy contexts can be introduced that include changes in international oil prices as well as the level and structure of domestic fuel taxes/subsidies. The model is essentially sectoral, as it covers both passenger and freight transport services across all transport modes and the focus is mainly on inland transport (especially road and rail). Each mode is further characterised in submodes (when relevant) and vehicle classes. Vehicle classes are further split to take into account different engine or powertrain technologies and vintages. Finally, powertrains are coupled with fuel blends that are consistent with the particular engine technology.

Although in extended form the model requires very detailed information that is not available in the Egyptian context, the core requires a minimum amount of data including information on the

\footnotetext{
5 An acronym: 'For Future Inland Transport Systems'.
} 
transport system in the base year (such as the composition of the transport fleet, i.e. numbers of cars, buses, trucks, lorries etc.) and the policy context, such as tax and subsidy rates. Other core variables needed for projections include the level and growth rates of GDP per capita, GDP growth, population, and new vehicle registrations (see Annex 1).

The evaluation of fuel and energy consumption using information on transport activity and vehicle characteristics is calculated using a decomposition of fuel use into transport activity, energy intensity and structural components, such as the type of transport service (passenger versus freight), mode, vehicle class and powertrain group (generally termed ASIF). This is then extended to measure $\mathrm{CO} 2$ emissions. In developing long-term projections, the vehicle-based ASIF approach is supplemented with relationships that link economic parameters with transportrelated ones (such as changes in the cost of travel with variations in travel per vehicle, or changes in income per capita with variations in vehicle ownership), as well as other specifics (i.e. choice models). As such, the model generates estimates of transport activity, vehicle use, fuel consumption and $\mathrm{CO} 2$ emissions.

\subsection{Applying the framework to Cairo}

Our main objective is to study the impact of policy measures - notably the domestic subsidy level for fuels as well as changes in international oil price - on CO2 emissions (as well as total energy use and vehicle stock) and based on that, to infer the level of PM10 emissions / concentrations and the likely impact on human health, using the measure already indicated in the discussion above, DALYs.

Our simulation exercises use 2014 as the base year and consider the impact of policy changes over both the medium term (up to 2024) as well as over the near term (up to 2020). We consider several scenarios in this exercise. For the medium term, we consider four cases in addition to the baseline:

(i) gradual decrease in fuel subsidies by $50 \%$;

(ii) gradual elimination of fuel subsidies $(100 \%)$;

(iii) gradual drop in fuel subsidies by $50 \%$ coupled with an increase in international price of oil by $20 \%$;

(iv) gradual elimination of subsidies $(100 \%)$ coupled with an increase in the international price of oil by $20 \%$.

Table 1 provides CO2 emissions for all four scenarios and the baseline. (Annex Table 1 also provides the corresponding changes in energy use associated with these emissions). There are a few empirical regularities that emerge. First, when a gradual fall in subsidies in the medium term is simulated, total $\mathrm{CO} 2$ emissions decrease by roughly 9 per cent. A gradual elimination of subsidies results in $\mathrm{CO} 2$ emissions dropping by 16 per cent when compared to the baseline scenario. A drop in energy use and CO2 emissions is also in evidence when there is a coupling of policies with external shocks. The third scenario couples a gradual decrease in energy subsidies with an increase in the international price of oil by 20 per cent. This policy simulation results in a drop in total CO2 emissions of around 16\%. Finally, as expected, the biggest change in energy use and $\mathrm{CO} 2$ emissions is observed when a policy of a gradual elimination of fuel subsidies is 
coupled with an increase in the international price of oil by 20 per cent. In this case, CO2 emissions fall by around 25 per cent.

The simulations are then repeated but with a shorter time period (up to 2020) for policy changes. The lower part of Table 1 gives the results. A more rapid elimination of fuel subsidies by 2020 results in a decrease in $\mathrm{CO} 2$ emissions by 15 per cent. Additionally, elimination of subsidies by 2020 coupled with an international price of oil increase by 20 per cent leads to a decline in energy use of roughly 20 per cent and an equivalent drop in CO2 emissions.

\subsection{Changes in modal composition}

Obviously, one of the main issues in pricing reform is the impact it may have on the relative demand for different types of transport and hence their varying contributions to total energy use and CO2 emissions. Reducing or eliminating subsidies should, for example, affect the propensity to use private vehicles relative to public transport, although the extent of substitution a range of factors including public transport pricing and the size of the public transport network as well as the extent to which provision can be scaled up in response to a shift in relative demand.

When considering the issue of modal competition, it needs to be remembered that the contribution of railways (both passenger and freight) in the overall emission of CO2 is low and does not exceed 1 per cent of total emissions. The great bulk of emissions and energy use is attributable to cars and buses in the passenger sector and trucks and lorries for freight ${ }^{6}$. In the scenarios presented in Table 1, this implies that although there are some minor changes in the overall contribution of $\mathrm{CO} 2$ emissions of various modes, the shares actually remain fairly stable over the years and with different scenarios. There is a minor increase in the share of CO2 emissions attributable to railways and other public transport modes. But for railways, in particular, to make an impact may require substantial investment in new capacity and infrastructure.

To simulate such an effect - albeit in very stylised form - we consider what might happen to emissions when we mimic the effect of a step-wise change - or positive investment shock - on the transport sector. Embedded in the model is an index of the transport system. It ranges from 0 to 1 where 1 is characteristic of a system with high population densities and very strong focus on public transport and 0 is characteristic of a system with little public transport and a strong focus on use of private vehicles. In setting the initial value of this index, we looked at a number of rankings and comparative scores and assigned Cairo a value of 0.3 , characteristic of a location with relatively weak public transport. We then employ two types of shocks aimed at capturing the possible impact of a large investment programme aimed at transport infrastructure. The first is a $20 \%$ gradual increase in the transport index over 10 years and the second is a $50 \%$ increase over the same period. We couple these shocks with changes to subsidies and increases in oil prices as used in Table 1.

Table 2 provides the main results. A positive shock to the transport index of $50 \%$ over 10 years, when coupled to either a $50 \%$ or $100 \%$ reduction of subsidies, results in lowering CO2 emissions by 20 and 29 per cent respectively. When considering the cases of a 20 and 50 per cent shock to

\footnotetext{
${ }^{6}$ This is comparable to international experience, whether in advanced or developing economies
} 
the transport index, coupled to the elimination of subsidies by 2024 and an oil price increase of $20 \%$, the fall in emissions amounts to around 26 and 32 per cent respectively. Compositionally, the share of emissions accounted for by the various types of public transport increases although not by very large magnitudes.

\subsection{Linking CO2 to PM10 emissions and DALYs}

There is limited information on the exact relationship between CO2 and concentration of particulates or PM10 emissions and hence on the appropriate conversions rates to be applied ${ }^{7}$. What evidence is available suggests that changes in CO2 emissions are associated with roughly proportional changes in PM10 emissions. Using data from the World Bank (Table 2.2; World Bank's Cairo Pollution study), we now project changes in the concentration of particulates (PM10) in Cairo for the scenarios used above. Our main assumption is that there is a linear relationship in the increase of CO2 and PM10 emissions. However, there are a few additional assumptions that we make in projecting PM10 emissions. First, we assume that an increase in PM10 particulates will be associated with an increase in the overall concentration of particulates in the Greater Cairo region. Second, based on the World Bank Greater Cairo Pollution Study, we assume that transport pollution represents roughly 15 per cent of total pollution in the city. Hence, a doubling of PM10 due to transport would be equivalent to 15 per cent of the change in overall PM10 emissions. It should be emphasized that this exercise is static as we hold everything else ceteris paribus, i.e. we do not consider changes in emissions/concentration due to industrial pollution and other factors. It is quite feasible that the policy changes we are simulating might also have an impact on those sectors. As such, we are probably underestimating the overall impact of fuel pricing changes.

The results of this exercise are presented in Table 3. Given the assumptions, changes in PM10 concentrations in various scenarios correspond to changes in CO 2 emissions from Table 1 above (Clearly, if changes in CO2 and PM10 emissions were not proportional, the estimates would have to be adjusted.) For the four scenarios to 2024, decreases in PM10 concentration range between 8 - 25 per cent compared with the base case. The drop in PM10 concentration in the shorter-term scenario (up to 2020) ranges between 15 and 20 per cent. Adding the changes in the transport index to simulate an increase in public transport, we can observe at the outer limit that there is a decrease of over 30 per cent in the concentration measure; a very substantial decline indeed.

After projecting PM10 emissions/concentration, we again use information from the World Bank Great Cairo Pollution study (Table 5.1: Total DALYs lost to pollution) and the ratios between PM10 concentrations and DALYs lost to project the total DALYs lost to transport pollution in the six scenarios. The results of this exercise are reported in Table 4 where the central calculation is of cumulative savings when comparing a particular scenario with the baseline case over the reference period. The table shows that a gradual 50\% fall in subsidies by 2024 is associated with

\footnotetext{
7 See Haikun Wang, Lixin Fu and Jun Bi, 'CO2 and pollutant emissions from passenger cars in China', Energy Policy, 39, 5, May, 2011, pp3005-3011 and M. Madireddy et al, 'Micro-Simulation of a Traffic Fleet to Predict the Impact of Traffic Management on Exhaust Emissions', Ghent, mimeo, 2010
} 
saving roughly 13,500 DALYs. A gradual elimination of fuel subsidies by 2024 saves nearly 23,000 DALYs. In the scenario where fuel subsidies are eliminated by 2024 and coupled with an increase in the international price of oil of 20 per cent, the DALYs saved amount to over 30,000. This corresponds to roughly 0.04 per cent of GDP. When we incorporate changes to the transport index in the simulations, at the maximum the cumulative savings of DALYs rise to around $0.07 \%$ of GDP. These are clearly not trivial numbers given that the estimated cost of total pollution in the Greater Cairo region amounts to around 0.2 per cent of GDP.

\section{Conclusion}

Our paper covers ground that has been relatively neglected both in analytical and policy terms; namely the externalities associated with energy subsidies. The latter are pervasive in the MENA region and cut across different types of economies, including those without significant natural resources. While the broad consequences of energy mis-pricing are well understood, the magnitude of the external effects associated with current pricing rules have attracted limited attention, let alone quantification. We attempt to correct this deficiency by focusing on two sectors - transport and agriculture - with a specific emphasis on the congestion and pollution costs associated with the first and the consequences for resource (water) depletion and crop selection in the case of the second. The paper is, however, exploratory both in a methodological and in an empirical sense, not least because of the absence of available data of sufficient quality. Nevertheless, we are able to identify the dominant channels through which energy subsidies create external costs and, particularly in the case of transport, begin to quantify their magnitudes in the context of Cairo. We view this exercise as a prelude to a more detailed study that will require further data assembly and collection.

In the case of transport in Cairo, we are able to quantify the impact of a change in energy pricing involving a reduction in subsidies on energy use and CO2 emissions. We then associate those emissions with that of particulates - as measured by PM10 - and through that channel make a link to health outcomes, as measured in terms of excess mortality and morbidity using the DALY measure. We find that there are non-trivial changes in energy use and CO2 emissions when energy subsidies are reduced. Our simulations indicate at their outer limit that a gradual elimination of fuel subsidies by 2024, when coupled with an increase in the international price of oil by 20 per cent, would result in CO 2 emissions falling by as much as 25 per cent. Eliminating subsidies by 2020 would lead to a decline in energy use of around 20 per cent with an equivalent drop in CO2 emissions. As regards the impact on health, subsidy elimination by 2024 would result in large order savings in terms of mortality and morbidity that amount to roughly 0.04 per cent of GDP. When factoring in changes in the use of different transport modes linked to a hypothetical increase in public investment in public transport infrastructure, at a maximum the cumulative savings of DALYs rise to around $0.07 \%$ of GDP. These are clearly significant given that an earlier World Bank study estimated the cost of total pollution in the Greater Cairo area to be around 0.2 per cent of GDP. In sum, our paper provides further evidence on the damaging and corrosive impact of energy subsidies by demonstrating that in one sector alone the external effects are large. Although the paper does not attempt to measure the overall costs associated with energy under-pricing on water use and scarcity, it uses available evidence to describe the 
impact on depletion including through crop selection, notably through the choice of irrigated crops. Using mainly evidence from Yemen, as well as data from the MENA region more widely, we show that energy mis-pricing has been associated with accelerated depletion rates. Given the relative scarcity of water resources in this region, the consequences are significantly adverse. Further analysis, and data collection, will allow more precise identification of these costs not only in these two sectors but also across a broader spectrum of sectors. 


\section{References}

1. Al-Ghandoor, A., J. Jaber, I. Al-Hinti and Y. Abdallat (2013) "Statistical assessment and analyses of the determinants of transportation sector gasoline demand in Jordan", Transportation Research Part A 50 (2013) 129-138.

2. Annema, J. (2002) "The policy context of transport: accessibility, safety and the environment”, In: Van Wee, B., M. Dijst, Verkeer en vervoen in hoofdjilnen, Bussum: Coutinho.

3. Aquastat, Food and Agricultural Organization of the UN, http://www.fao.org/nr/water/aquastat/main/index.stm

4. Bekhet, H. (2010) "Energy Use in Agriculture Sector: Input-Output Analysis", International Business Research, Vol.3, No.3, July 2010.

5. Brand, Dan. (2009), Impacts of Higher Fuel Costs, Federal Highway Administration, (www.fhwa.dot.gov); at www.fhwa.dot.gov/policy/otps/innovation/issue1/impacts.htm.

6. Camagni, R., M. Gibelli and P. Rigamonti (2002) "Urban mobility and urban form: the social and environmental costs of different patterns of urban expansion", Ecological Economics 40 (2002) 199-216.

7. De Witte, A., J. Hollevoet, F. Dobruszkes, M. Hubert, C. Macharis (2013) "Linking modal choice to motility: A comprehensive review", Transportation Research Part A 49, pp. 329-341.

8. Doumani, F. (2011) Greater Cairo Air Pollution: Cost of Environmental Degradation, unpublished report, 2011.

9. Egypt Ministry of Finance. http://www.mof.gov.eg/english/Pages/Home.aspx

10. Egypt Ministry of Transport. http://www.mot.gov.eg/

11. Externalities of Energy, ExternE project, Method for Estimation of Physical Impacts and Monetary Valuation for Priority Impact Pathways, mimeo, London, UK.

12. Forkenbrock, D. (2001) "Comparison of external costs of rail and truck freight transportation", Transportation Research Part A, 35, pp. 321-337.

13. Forkenbrock, D. (1999) "External costs of intercity truck freight transportation", Transportation Research A 33 (7/8), pp 505-526.

14. Gillingham, Kenneth (2010), Identifying the Elasticity of Driving: Evidence from a Gasoline Price Shock in California, Stanford University (www.stanford.edu); at www.stanford.edu/ kgilling/Gillingham_IdentifyingElasticityofDriving.pdf.

15. Global Road Safety www.grsproadsafety.org/

16. Goodwin, Phil, Joyce Dargay and Mark Hanly (2004), "Elasticities of Road Traffic and Fuel Consumption With Respect to Price and Income: A Review," Transport Reviews (www.tandf.co.uk), Vol. 24/3, May, pp. 275-292.

17. Gul, A., F. Rida, A. Aw-Hassan, O. Buyukalaca (2005) "Economic analysis of energy use in groundwater irrigation of dry areas: a case study in Syria", Applied Energy 82 (2005) 285-299.

18. He, L. W. Tyner, and R. Doukkali (2013) "Policy options to improve water allocation efficiency: analysis on Egypt and Morocco", mimeo, Purdue University, USA.

19. Hymel, Kent, Kenneth A. Small and Kurt Van Dender (2010), "Induced Demand And Rebound Effects In Road Transport," Transportation Research B 
(www.elsevier.com/locate/trb), Vol. 44, Issue 10, December, pp. 1220-1241; at www.socsci.uci.edu/ ksmall/Rebound_congestion_27.pdf.

20. IFPRI (2011) "The political economy of agricultural policy reform in India : fertilizers and electricity for irrigation", IFPRI research monograph, 2011.

21. INFRAS/IWW (2004) "External Cost of Transport: update study", final report, mimeo, Zurich, Switzerland, 2004.

22. Institute for Health Metrics and Evaluation. <http://www.healthdata.org/>

23. International Monetary Fund (2013) "Energy subsidy reform: lessons and implications", IMF Working Paper, Washington DC, USA

24. Jha, K., S. Pal and A. Singh (2012) "Changing Energy-use Pattern and the Demand Projection for Indian Agriculture”, Agricultural Economics Research Review, Vol. 25(No.1) January-June 2012 pp 61-68.

25. Johansson, Olof and Lee Schipper (1997), "Measuring the Long-Run Fuel Demand for Cars," Journal of Transport Economics and Policy, Vol. 31, No. 3, pp. 277-292.

26. Li, Shanjun, Joshua Linn and Erich Muehlegger (2011), Gasoline Taxes and Consumer Behavior, Stanford (http:/ / economics.stanford.edu); at http://economics.stanford.edu/files/muehlegger3_15.pdf.

27. Limtanakool, N., Dijst, M. and Sschwanen, T.(2006) "On the participation in mediumand long-distance travel: a decomposition analysis for the UK and the Netherlands, Tijdschrift voor Economische en Sociale Geografie, 97, pp. 389-404.

28. Litman, Todd (2012) Changing Vehicle Travel Price Sensitivities The Rebounding Rebound Effect (www.vtpi.org)

29. Litman, Todd. (2004). Evaluating Public Transit Benefits and Costs, VTPI (www.vtpi.org).

30. Mayeres et al., (1996) "The marginal external costs of urban transport", Transportation Research Part D 2: 111-130.

31. Mizutani, F., Y. Suzuki and H. Sakai (2011) "Estimation of Social Costs of Transport in Japan”, Urban Studies, 48 (16), pp. 3537-3559.

32. Monzon, A and M-J. Guerrero (2004) "Valuation of social and health effects of transport-related air pollution in Madrid (Spain)", Science of the Total Environment $334-335$ (2004) 427-434.

33. Nelson, H., T. Roe, R. Smith, D. de Leon Barido, and E. Foufoula-Georgiou (2013) "The Shadow Value of Groundwater in Punjab, India: An analysis in an Economy-Wide Context", University of Minnesota, Institute of the Environment, 2013.

34. Ostro, B., R. Broadwin and M. Lipsett (2004) "Fine Particles and Daily Mortality in Nine California Counties: Results From Calfine.” Epidemiology. Volume 15, Number 4.

35. Pope, C. A., M. Thun, M. Namboodiri, D. Dockery, J. Evans, F. Speizer, and C. Heath (1995) "Particulate Air Pollution as a Predictor of Mortality in a Prospective Study of U.S. Adults." Am. J. Crit. Care Med. 151: 669-74.

36. Pope, C. A., R. T. Burnett, M. J. Thun, E. E. Calle, D. Krewski, K. Ito, and G. Thurston (2002) "Lung Cancer, Cardiopulmonary Mortality and Long Term Exposure to Fine Particulate Air Pollution.”, Journal of the American Medical Association 287(9): 11321141. 
37. Rentziou, A., K. Gkritza and R. Souolyerette (2012) "VMT, energy consumption, and GHG emissions forecasting for passenger transportation", Transportation Research Part A 46 (2012), pp. 487-500.

38. Robuste, F., A. Lopez-Pita and M. Capdet (2001) "Social cost of metropolitan passenger transport in Barcelona", Transactions on the Built Environment vol. 52, pp. 751-763.

39. Rojo, M., H. Gonzalo-Orden, L. dell'Olio, and A. Ibeas (2012) "Relationship Between Service Quality and Demand for Inter-urban Buses.” Transportation Research Part A 46: 1716-1729.

40. Schafer, A (2000) Regularities In Travel Demand: An International Perspective, Journal of Transportation and Statistics, December 2000.

41. Schimek, Paul (1997), "Gasoline and Travel Demand Models Using Time Series and Cross-Section Data from the United States," Transportation Research Record 1558, TRB (www.trb.org), pp. 83-89.

42. Small, K. (2012) "Energy policies for passenger motor vehicles", Transportation Research Part A 46 (2012) 874-889.

43. Small, Kenneth and Kurt Van Dender (2005), The Effect of Improved Fuel Economy on Vehicle Miles Traveled: Estimating the Rebound Effect Using U.S. State Data, 19662001, University of California Energy Institute's (UCEI) (www.ucei.berkeley.edu); at www.ucei.berkeley.edu/PDF/EPE 014.pdf.

44. Spiller, Elisheba and Heather M. Stephens (2012), The Heterogeneous Effects of Gasoline Taxes: Why Where We Live Matters, Resources for the Future (www.rff.org); at www.rff.org/RFF/Documents/RFF-DP-12-30.pdf; complete report at http://papers.ssrn.com/sol3/papers.cfm?abstract_id=2129396.

45. Stanley, J.K., Hensher, D.A., Loader, C. (2011) Road transport and climate change: Stepping off the greenhouse gas. Transportation Research Part A, 45, 1020-1030.

46. World Bank (2013) "For better or for worse: air pollution in greater Cairo", World Bank Concept note, April, 2013.

47. World Bank (2010) "Cairo - Congestion Study", mimeo, Washington DC, USA.

48. World Development Indicators. <www.wdi.org>

49. World Health Organization (1999) "Economic evaluation of health impacts due to road traffic related air pollution", WHO Europe, Copenhagen, mimeo. 


\section{Annex 1: Data requirements}

The data requirements for the model are grouped as follows: (i) socio-economic data- inputs on macroeconomic and demographic data, such as GDP and population, which are needed for projections, (ii) modelling switches - definition of the time period as well as the engine or powertrain selection procedure for forecast new vehicle registrations, (iii) user inputs - characteristics of the transport system in the base year including characteristics of the vehicle fleet, (iv) transport system data on the evolution of the transport system over time. These are mainly indices that determine characteristics of the passenger transport system and — for freight — inputs about the economic structure, such as the type of goods in the economy as well as characteristics of their movement, (v) user inputs - inputs that enable the allocation of transport activity or the fuel characteristics (e.g. emission factors per energy unit that lead to CO2 emitted by different fuel blends) over time, (vi) powvertrain potential - technical data on the performance of the vehicles and the powertrain ratios that give fuel consumption for different technologies, (vii) powvertrain shares inputs on the technological variations in projected new vehicle registrations that are applied for exogenously determined powertrain selection, (viii) powertrain availability - data on the availability of each technology over time, (ix) cost inputs by powertrain - inputs over time on vehicle cost for each technology, (x) demand parameters - these include parameters that determine the S-curves generated by transport demand as a function of GDP per capita and the relationship between the cost of driving and different types of transport activity.

The limited availability of transport data for Egypt means that we have mainly data for the vehicle stock (motorcycles, cars, buses (in the case of passenger transport) and trucks and lorries (in the case of freight transport)). Additionally, we use data from the World Development Indicators (WDI) on population, GDP per capita, GDP per capita growth and population growth. Data on prices of gasoline and diesel are also taken from WDI. For other inputs such as powertrains, parameter estimates and so on - given the comparability of the transport sectors between Egypt and Tunisia - information is used from a very detailed dataset for Tunisia which has already been applied in a pilot study by the developers of the FORFits model. All of the data above correspond to actual values in 2012 . 
Table 1. Egypt- main outputs: FORFits simulation exercise (CO2 emissions) - subisdies and international oil price change

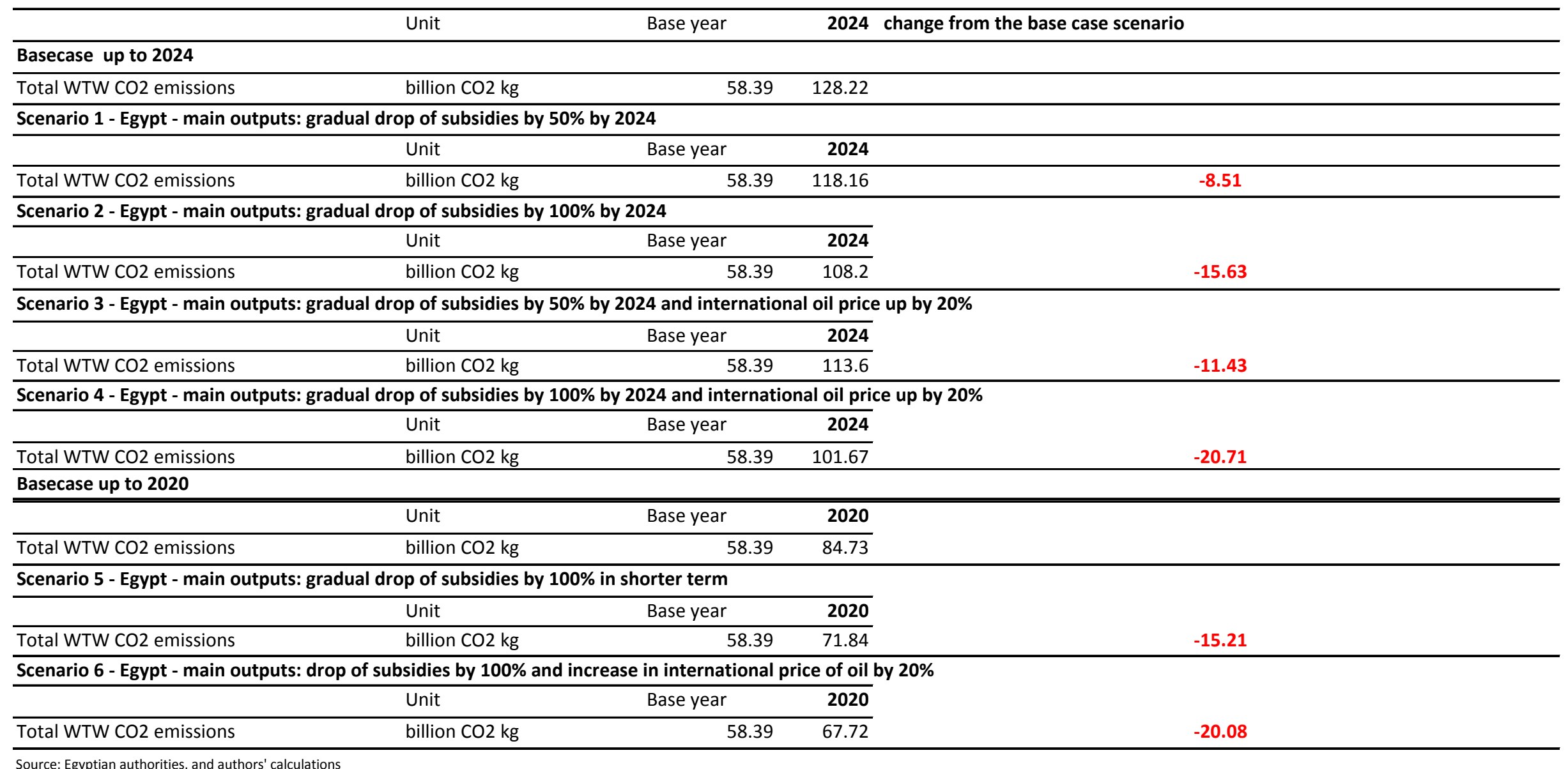

Source: Egyptian authorities, and authors' calculations 
Table 2. Egypt- main outputs: FORFits simulation exercise (CO2 emissions) - subsidies, international oil price and transport index change

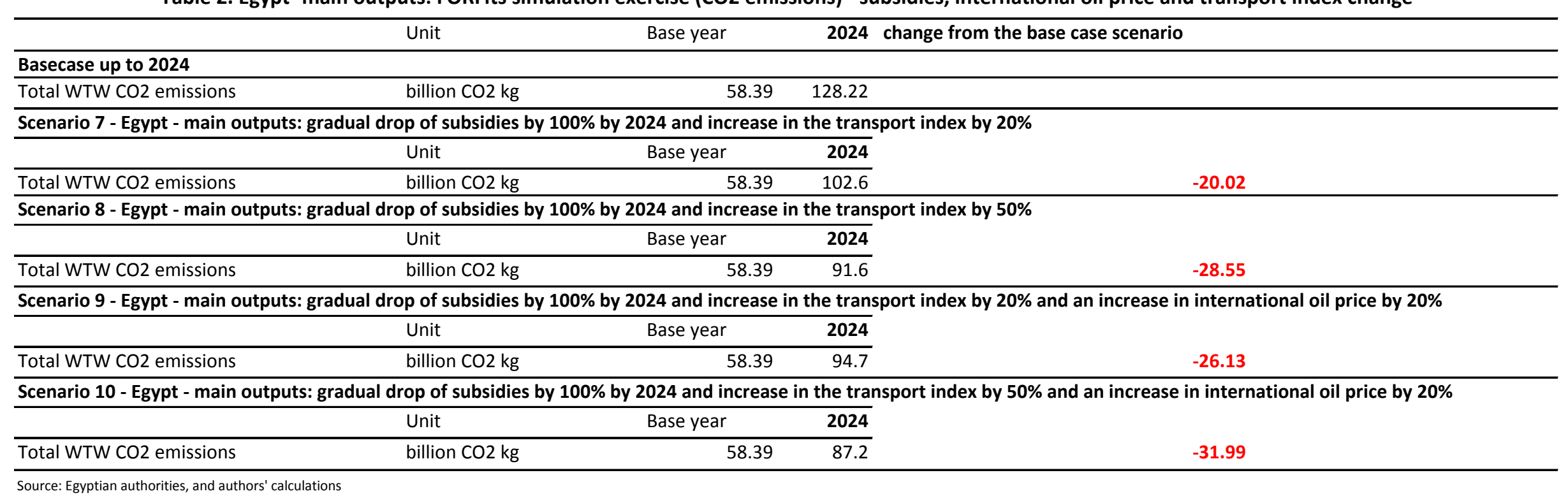

Source: Egyptian authorities, and authors' calculations 
Table 3. PM10 projected concentration in Cairo

\begin{tabular}{|c|c|c|c|c|c|c|c|c|c|c|c|c|}
\hline & & 2014 & 2015 & 2016 & 2017 & 2018 & 2019 & 2020 & 2021 & 2022 & 2023 & 2024 \\
\hline basecase up to 2024 & PM10 concentration & 142 & 144.13 & 146.26 & 148.39 & 150.52 & 152.65 & 154.78 & 156.91 & 159.04 & 161.17 & 163.3 \\
\hline scenario 1 & PM10 concentration & 142 & 142.82 & 143.64 & 144.46 & 145.28 & 146.1 & 146.92 & 147.74 & 148.56 & 149.38 & 150.2 \\
\hline scenario 2 & PM10 concentration & 142 & 141.55 & 141.1 & 140.65 & 140.2 & 139.75 & 139.3 & 138.85 & 138.4 & 137.95 & 137.5 \\
\hline scenario 3 & PM10 concentration & 142 & 142.26 & 142.52 & 142.78 & 143.04 & 143.3 & 143.56 & 143.82 & 144.08 & 144.34 & 144.6 \\
\hline scenario 4 & PM10 concentration & 142 & 140.8 & 139.6 & 138.4 & 137.2 & 136 & 134.8 & 133.6 & 132.4 & 131.2 & 130 \\
\hline basecase up to 2020 & & 142 & 142.96 & 143.92 & 144.88 & 145.83 & 146.79 & 147.75 & & & & \\
\hline scenario 5 & PM10 concentration & 142 & 139.27 & 136.54 & 133.81 & 131.08 & 128.35 & 125.6 & & & & \\
\hline scenario 6 & PM10 concentration & 142 & 139.48 & 136.96 & 134.44 & 131.92 & 129.4 & 116.72 & & & & \\
\hline \multicolumn{13}{|l|}{ Transport index } \\
\hline scenario 7 & PM10 concentration & 142 & 140.87 & 139.74 & 138.61 & 137.48 & 136.35 & 135.22 & 134.09 & 132.96 & 131.83 & 130.7 \\
\hline scenario 8 & PM10 concentration & 142 & 139.56 & 137.12 & 134.68 & 132.24 & 129.8 & 127.36 & 124.92 & 122.48 & 120.04 & 117.6 \\
\hline scenario 9 & PM10 concentration & 142 & 139.89 & 137.78 & 135.67 & 133.56 & 131.45 & 129.34 & 127.23 & 125.12 & 123.01 & 120.9 \\
\hline scenario 10 & PM10 concentration & 142 & 139 & 136 & 133 & 130 & 127 & 124 & 121 & 118 & 115 & 112 \\
\hline
\end{tabular}

based on original Table 2.2. World Bank Cairo Pollution report 
Table 4. Total DALYs lost to transport pollution

\begin{tabular}{|c|c|c|c|c|c|c|c|c|c|c|c|c|}
\hline & & 2014 & 2015 & 2016 & 2017 & 2018 & 2019 & 2020 & 2021 & 2022 & 2023 & 2024 \\
\hline basecase up to 2024 & transport pollution DALY & 24276.68 & 24618.6 & 24982.42 & 25346.24 & 25710.07 & 26073.89 & 26437.71 & 26801.53 & 27165.35 & 27529.17 & 27893 \\
\hline scenario 1 & transport pollution DALY & 24276.68 & 24276.68 & 24416.06 & 24555.44 & 24694.83 & 24834.21 & 24973.6 & 25112.98 & 25252.37 & 25391.75 & 25537 \\
\hline scenario 2 & transport pollution DALY & 24276.68 & 23873.85 & 24276.68 & 24199.25 & 24121.83 & 24044.4 & 23966.98 & 23889.56 & 23812.13 & 23734.71 & 23657 \\
\hline scenario 3 & transport pollution DALY & 24276.68 & 24618.6 & 24276.68 & 24320.96 & 24365.25 & 24409.54 & 24453.83 & 24498.12 & 24542.4 & 24586.69 & 24631 \\
\hline scenario 4 & transport pollution DALY & 24276.68 & 24105.71 & 23900.27 & 23694.82 & 23489.37 & 23283.93 & 23078.48 & 22873.03 & 22667.59 & 22462.14 & 22257 \\
\hline basecase up to 2020 & transport pollution DALY & 24276.68 & 24440.54 & 24604.41 & 24768.28 & 24932.15 & 25096.01 & 25259.88 & & & & \\
\hline scenario 5 & transport pollution DALY & 24276.68 & 23809.95 & 23343.22 & 22876.49 & 22409.76 & 21943.04 & 21470.9 & & & & \\
\hline scenario 6 & transport pollution DALY & 24276.68 & 23845.85 & 23415.02 & 22984.2 & 22553.37 & 22122.55 & 19955.31 & & & & \\
\hline \multicolumn{13}{|l|}{ Transport index } \\
\hline scenario 7 & transport pollution DALY & 24276.68 & 24083.49 & 23890.3 & 23697.11 & 23503.92 & 23310.74 & 23117.55 & 22924.36 & 22731.17 & 22537.99 & 22344.8 \\
\hline scenario 8 & transport pollution DALY & 24276.68 & 23859.53 & 23442.38 & 23025.23 & 22608.08 & 22190.93 & 21773.78 & 21356.64 & 20939.49 & 20522.34 & 20105.19 \\
\hline scenario 9 & transport pollution DALY & 24276.68 & 23915.94 & 23555.21 & 23194.48 & 22833.75 & 22473.02 & 22112.29 & 21751.56 & 21390.83 & 21030.1 & 20669.37 \\
\hline scenario 10 & transport pollution DALY & 24276.68 & 23763.79 & 23250.9 & 22738.01 & 22225.13 & 21712.24 & 21199.35 & 20686.46 & 20173.58 & 19660.69 & 19147.8 \\
\hline
\end{tabular}

based on original Table 5.1. World Bank Cairo Pollution report 
Table A1. Egypt- main outputs: FORFits simulation exercise (energy use) - subisdies and international oil price change

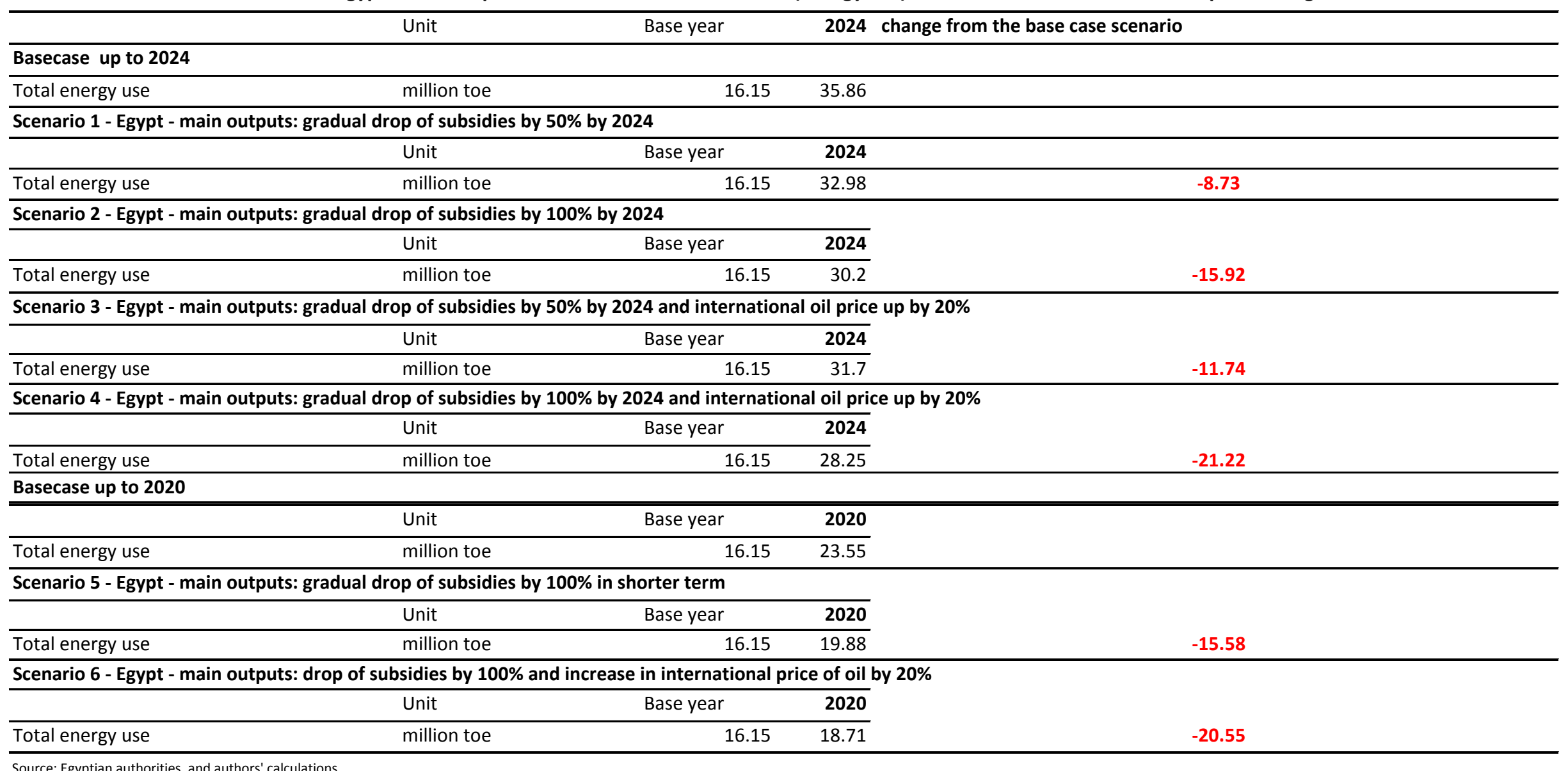

Source: Egyptian authorities, and authors' calculations 
Table A2. Egypt- main outputs: FORFits simulation exercise (energy use) - subsidies, international oil price and transport index change

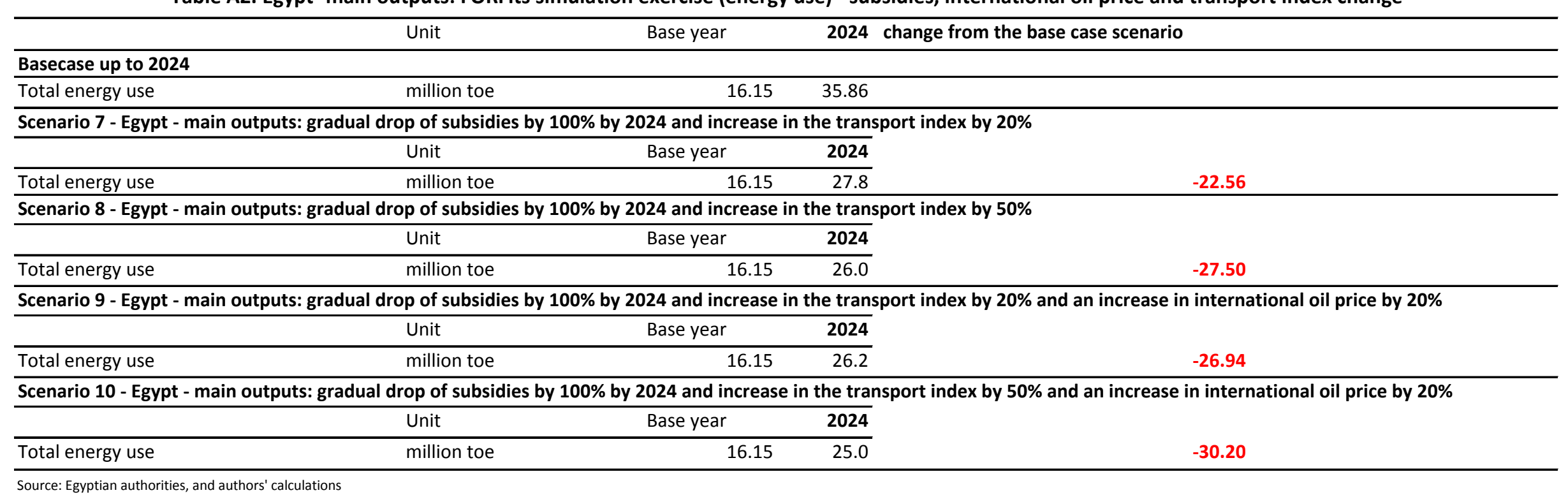

Source: Egyptian authorities, and authors' calculations 